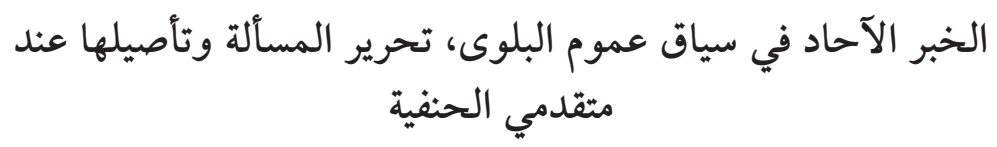

\title{
Mütekaddimûn Dönemi Hanefî Âlimlerinin 'Umûmu'l- Belvâ Bağlamında Âhâd Haberle İlgili Görüşleri
}

\author{
The Isolated Hiadith in the Context of 'Umūm al-Balwā: \\ Examining the Issue in the Light of the First Generation of Hanafi \\ Scholars

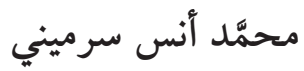 \\ Mohamad Anas SARMINI*

$$
\begin{aligned}
& \text { الملخص: يناقش هذا البحث مسألة عدول الحنفية عن العمل بالحديث الآحاد، فيما إذا جاء فيما تعم }
\end{aligned}
$$

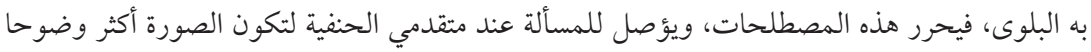

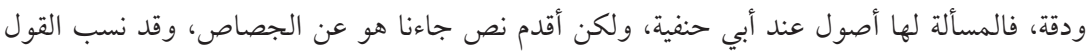

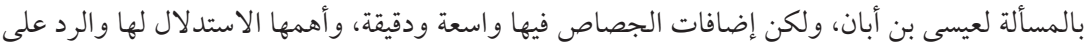

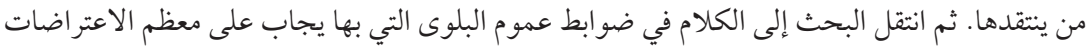

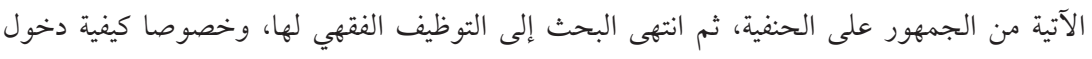

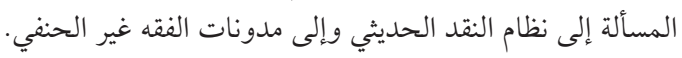

$$
\begin{aligned}
& \text { الكلمات الففتاحية: عموم البلوى، الخبر الآحاد، الجصاص، عيسى بن أبان، رد الحديث }
\end{aligned}
$$

Öz: Bu çalışma, Hanefî mezhebinde “"umûmu'l-belvâ” ile ilgili âhâd haberlerin terk edilmesi meselesini ele almaktadır. Çalışmada öncelikle konuyla ilgili terimler incelenmiş ve ilk dönem Hanefî âlimlerinin görüşleri ele alınarak konunun vuzuha kavuşturulması hedeflenmiştir. Ebû Hanîfe'den nakledilen görüşlerde konuyla ilgili bazı esaslar bulunsa da bu meselede bize ulaşan en erken metin Cessâs'a aittir. Cessâs, umûmu'l-belvâyla ilgili zikrettiği görüşleri Îsâ b. Ebân’a nispet etmekle birlikte zikrettiği deliller ve muhaliflerin tenkitlerine verdiği cevaplarla konuyla ilgili ilave açıklamalar da yapmıştır. Çalışmada, umûmu'l-belvânın şartları da ele alınmıştır. Söz konusu şartlar, cumhurun bu konuda Hanefîlere yönelttiği tenkitlere cevap niteliği taşımaktadır. Son olarak konunun, fikhî meselelerdeki işlevselliği ve Hanefî mezhebi dışındaki fıkıh literatürüne ve hadis tenkit metoduna girişi bazı örnekler zikredilerek ele alınmış ve bu şekilde çalışma nihayete erdirilmiştir.

Anahtar Kelimeler: 'Umûmu'l-belvâ, âhâd haber, Hanefî mezhebi, Cessâs, İsa b. Ebân.

* Dr. Öğr. Üyesi, İstanbul 29 Mayıs Üniversitesi, asarmini@29mayis.edu.tr

Orcid No: 0000-0002-6396-374X 


\title{
The Isolated Hadìth in the Context of 'Umūm-al-Balwā: Examining the Issue in the Light of the First Generation of Hanafī Scholars
}

\begin{abstract}
The aim of this research is to discuss the issue of Hanafî scholars' abandoning the isolated hadith in the context of 'Umūm al-Balwā, which is one of the controversial issues in contrast to Ahl al-Ra'y. Most of the Mutakallimūn and Muhaddithün do not accept this criterion in differentiating between the accepted prophetic narrations and the rejected ones.
\end{abstract}

There are two methodologies in the classical Islamic points of view that govern this topic. The first is the causal approach, which seeks the integration of evidence and the coherence in the texts. In the context of the supposed conflict of evidence, they resort to interpretation, they do not accept breaking the general rules except for the context of certainty, which means the authentic certain mutawätir or the mashhür hadìth.

The Second is the apparent "Zāhirì" approach that looks for the individual evidence and texts. It works on making all of the narrations applicable. In the context of the contradiction between the general and special texts, they erase the conflict by specialization or restriction, and resort to the interpretation only when it is necessary.

These two approaches appeared during the earliest Islamic era, when the companions interpreted the famous hadith of Banū Qurayẓa about praying the 'Așr prayer and then they appeared in the following historical periods, especially in the main two streams of Sunnī schools, namely Ahl al-Hadìth and Ahl al-Ra'y.

One of the results of these two methods is the issue of 'Umüm al-Balwa which is appealed to by the first approach. It means not accepting the isolated hadith which reaches us by the individual narrators and rejecting it in the case that its details and contexts requires it to be mutawātir, because the content requires that not only should many people have learnt it but that it then needs to have been transmitted. When such a hadith brings us down to one person, it makes itself suspicious, and it needs to be reconsidered as to whether it will be accepted or left to the original rules and ahkām. It is clear that the second approach does not accept such an argument. That approach deals with each hadith as an independent hadith.

So, this issue is located in a common area between the Ușūl al-hadìth and Ușül al fiqh. Both the Muhaddithūn and the Ușūliyyūn studied it. This research aims to take a profound look at this issue in the earliest texts of Ahl al-Ra'y. Thus, to explore it and trying to understand it from their point of view and not the later views, i.e. the mutaiakhirūn, of the Hanafī scholars.

The research informs us of much of the details about this issue among the earliest Hanafì scholars both theoretically and practically. It first examines the terms related to this subject and examines the issue within the method of the first generation of Hanafì scholars in order to reach the accurate result. As a matter of this fact, there are in Abū Hanifa's traditions some implications to this view about 'Umūm al-Balwā. However, the oldest text that has reached us is from Jașsāṣ. He related these ideas and their explanations to 'İsā b. Abān. Jaș̣āṣ brought forward proofs, justification with regards to this issue and tried to disprove the doubts against it.

The research is mainly depending on the works of Jașșāṣ, Sarakhsī and Qudūrī. That is not to state that other scholars of that time are any less important, however, they did not focus on this issue nor did they resort to it in their $u s \bar{u} l$ or furü.' Moreover, this study addresses the above mentioned conditions of 'Umūm al-Balwā and has focused on both the theoretical and the practical sides found in the Hanafi corpus. 
Though, the earliest scholars suggested to the following Ḥanafĩ scholars some restrictions to 'Umūm al-Balwā issue. It seems that these restrictions were not taken into consideration by the later scholars. This research claims that if these restrictions were significantly studied, the criticism of Ahl Al-Hadith would be decreased to some extent. This is because the research attempts to prove that this kind of thinking and dealing with the hadith is a part of the science of hadith itself.

This study suggests four main restrictions for 'Umūm al-Balwā, which are as follows:

The first: 'Umūm al-Balwā must be presumed to be in the context of the authentic hadith and not amongst the weak. The second: 'Umūm al-Balwā is presumed to be in the isolated hadīth, which are neither mashhūr nor mutawātir. The third: 'Umūm al-Balwā is acknowledged to be by the narrator who does not have a special qualification and therefore qualifies this hadith to be heard on its own. The fourth: 'Umūm al-Balwā is concerned with the hadiths of fard (obligatory) and harām (prohibited), and that the provisions of such types of obligations and prohibitions are not taken from the Sunnah nor the makrūh. In the absence of the first condition most of the Muhaddithūn will accept the point of Ahl al-Ray. Also, in the absences of the second, third and fourth condition Ahl al-Ra'y will deal with the hadiths in terms of Muhaddithūn.

Finally, the article will focus on some cases of how this issue addresses the method of the Muhaddithūn and the other schools of fiqh.

Keywords: 'Umūm al-Balwā, isolated ḥadīth, 'Īsā b. Abān, Jașșāṣ, Ḥanafĩ school of jurisprudence 


\section{المقدمة}

الحمد لله رب العالمين، وأفضل الصلاة وأتم التسليم على سيدنا محمَّد، وعلى آله وصحبه أجمعين.

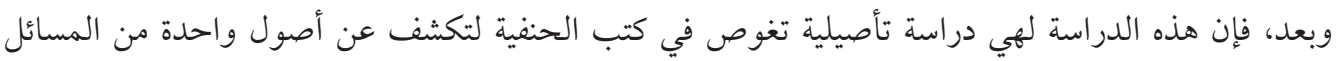

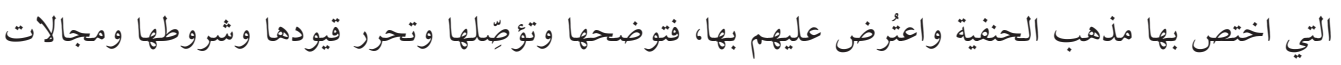
تطبيقاتها.

تأتي أهمية هذا البحث من كونه يتعامل مع أصول مذهب الحنفية في مسألة حديثية مهمة هي رد حديث

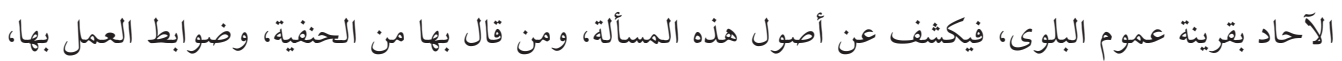

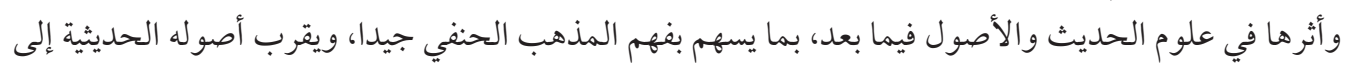

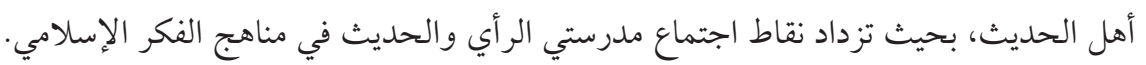
للبحث عدة أهداف يرمي إلى الوصول إليها، وهي الآتية:

• تحرير مسألة عموم البلوى، وبيان سياقها الدقيق ومجال العمل بها عند الحنفية. تحرير نسبة هذه المسألة إلى مشايخ الحنفية المتقدمين ضمن القرون الأربعة الأولى. بيان موضع العمل بهذه المسألة وحدود توظيفها في الفقه. بيان القيود التي اشترطها الحنفية في إعمالهم لهذه المسألة. • الموازنة بين رأي الحنفية في المسألة وبين آراء من انتقدهم فيها. • بيان مدى العلاقة بين عموم البلوى وبين قواعد قبول الحديث ورده.

يعتمد البحث المنهج الاستقرائي أولا، ثم الاستنتاجي والتحليلي في استنطاق ما جمعه الباحث من نقول ومعلومات متصلة بالبحث، للوصول إلى القواعد والضو ابط الكلية التي تحكم مسألة عموم البلوى عند الحتب الحنفية.

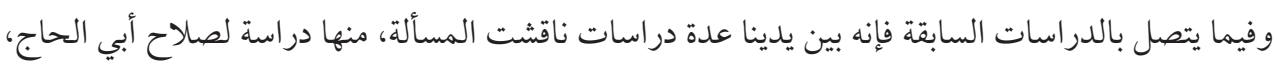
حكم حديث الآحاد فيما تعم به البلوى عند الحنفية وتطبيقاته في كتبهم، منشورة في مجلة المبات المدونة.

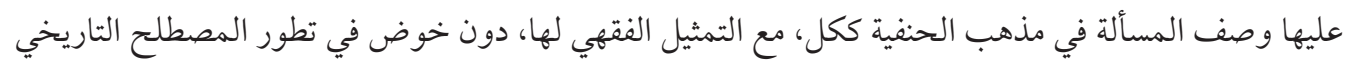

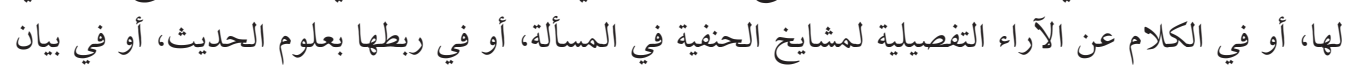
قيودها وضو ابطها.

1 أبو الحاج، صلاح، حكم حديث الآحاد فيما تعم به البلوى عند الحنفية وتطبيقاته في كتبهم، مجلة المدونة الصادرة عن مجمع الفقه

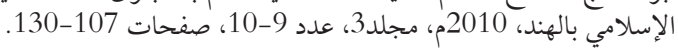


وكذلك لدينا دراسة لعبد الرحمن القرني، خبر الآحاد فيما تعم به البلوى، منشورة في موقع المسلمين، 2

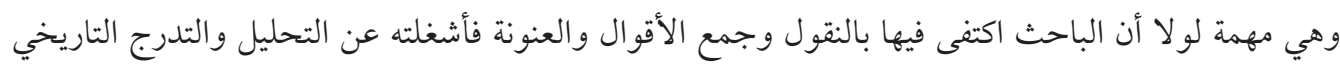
لظهور المسألة وتأثيرها في علوم الحديث.

ولا يخفى أن هناك بعض الدراسات التي ناقشت أصول الحديث عند الحنفية عموما كدراسة عبد المجيد

$$
\text { التركماني دراسات في أصوله الحديث على منهج الحنفية. }
$$

وقد اقتضت أهداف البحث ومنهجه أن يكون تقسيم البحث على ثلاثة مباحث يسبقها مبحث تمهيدي أدرس فيه المنطلقات النظرية للبحث، وهي الآتية:

المبحث الأول: نظرية الحنفية في عموم البلوى، بناؤها والاستدلال لها. المبحث الثاني: ضوابط القول بعموم البلوى، وأسباب العدول عن الحديث لأجله. المبحث الثالث: التوظيف الفقهي العملي لعموم البلوى عند الحنفية وغيرهم. وتضمن كل مبحث المطالب والفروع المناسبة، ثم ختمت البحث بالنتائج العلمية وبقائمة المصادر. واللَّ نسأله التوفيق.

\section{مبحث تمهيدي: المنطلقات النظرية للبحث أولا: التعريف بأهم مصطلحات البحث}

قبل البدء بهذا البحث لا بدَّ من تعريف أهم مصطلحاته، وهي العموم، والبلوى، وعموم البلوى، والخبر الآحاد، والسنة المشهورة.

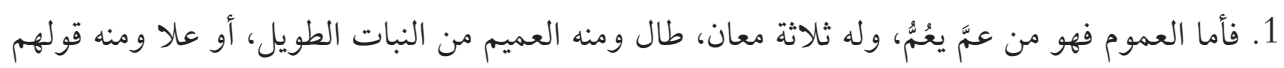

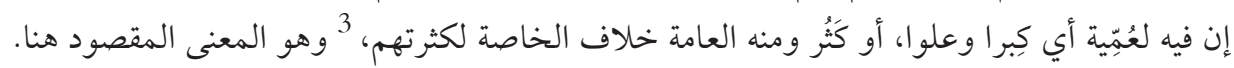
2. وأما البلوى فهي من بلا يبلو، وله معنيان: إخلاق الشيء، ومنه بلي الثوب. والاختبار كقوله (اونبلوكم

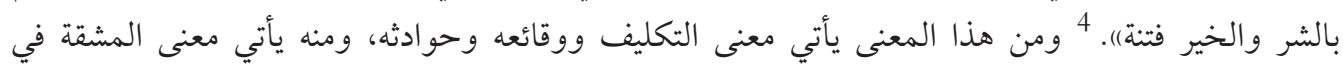
التكليف.

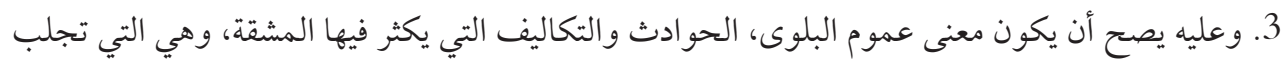

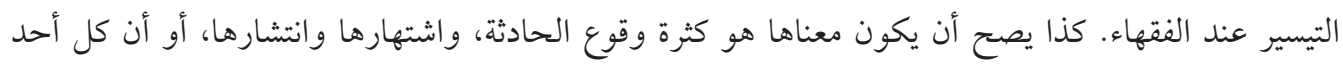

$$
\begin{array}{r}
\text { انظر } \\
4
\end{array}
$$


يحتاج إلى معرفته. فالمعنى الأول هو الشائع لدى الأصوليين، والثاني هو المقصود عند الحنفية منهم فحسب،

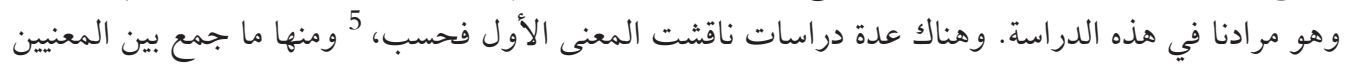
في الدراسة، 6 ومنها ما اختص بالمعنى المقصود عند الحنفية، كدراستي صلاح أبي الحاج وعبد الرحمن القرني اللتين أتينا لذكرهما في الدراسات السابقة.

4. الخبر الآحاد، عرَّفه أبو الحسن البزدوي (ت:482ه، 1089م)، بقوله كل خبر يرويه الواحد أو الاثنان فصاعدًا لا عبرة للعدد فيه بعد أن يكون دون المشهور والمتواتر، 7 وهو نفسه عند المحدثين لو لا أنهم يجعلونه قسيم المتو اتر فحسب.

5. السنة المشهورة، وهي مصطلح إشكالي بين علماء أصول الفقه من الحنفية وبين علماء الحديث، فالحديث ينصرف إلى الرواية القولية عن النبي أو أصحابه في تمييز معروف عند أهل الحديث، أما السنة فهي

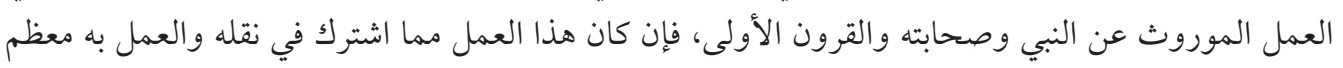

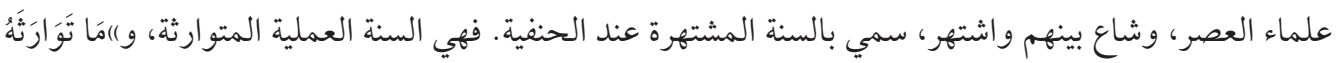

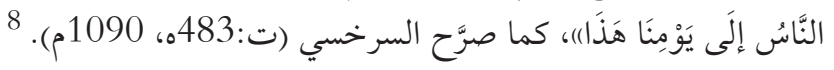
وعليه يكون الخبر الآحاد إذا جاء في سياق عموم البلوى، أي في المسائل الشائعة المشتهرة التي يحتاج

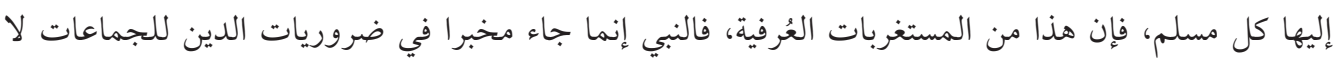

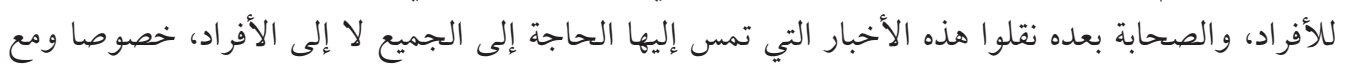

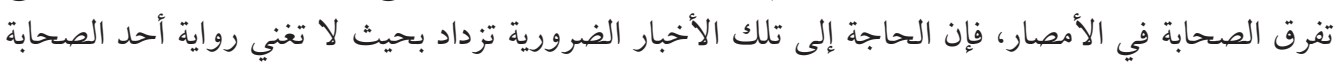
في إحدى المدن عن رواية غيره في مدينة أخرى.

فإذا ما جاءت رواية في موضوع تمس إليه الحاجة ويكثر دورانها على الأشخاص وفي الأزمان، عن راو

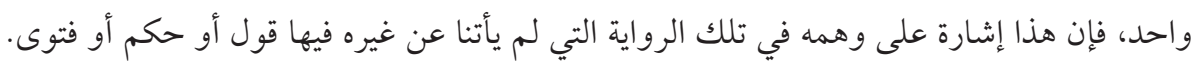
ثانيا: حدود المسألة، التفرد بين المحدثين والحنفية سياق مسألة الخبر الآحاد فيما تعم به البلوى، هو سياق الحديث الفرد، وتفرد الثقات، فأما الحديث المتواتر

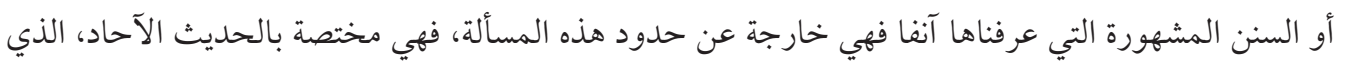

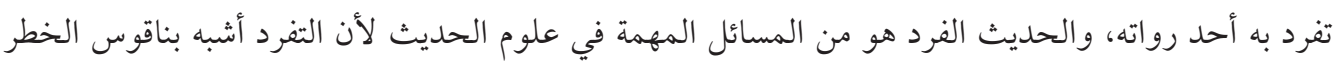

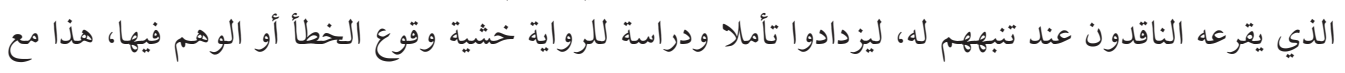
حسن الظن بعدالة وضبط الراوي.

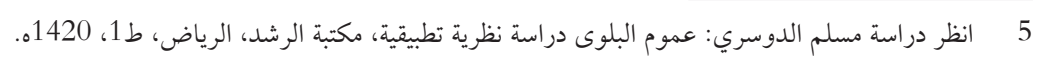

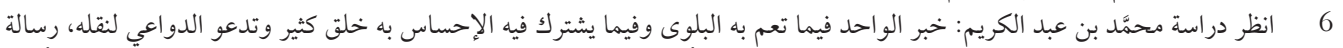

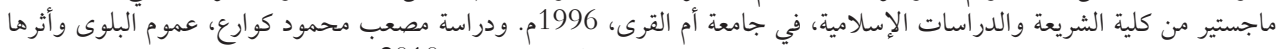

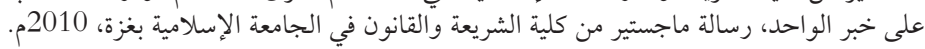

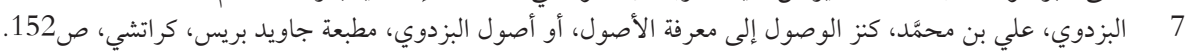
8 


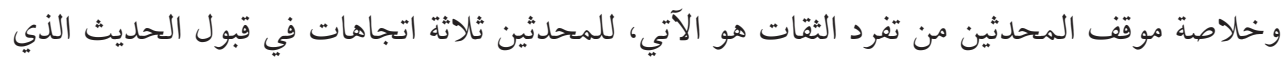

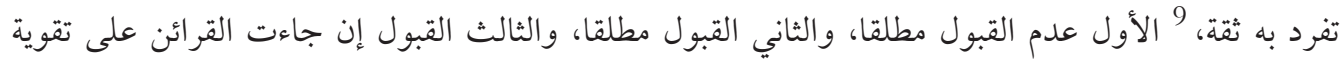

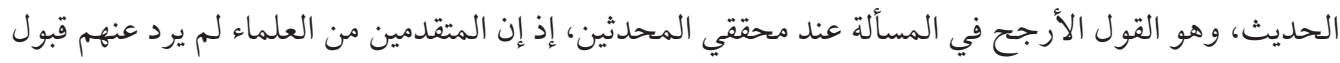

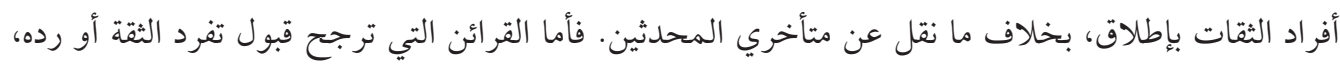

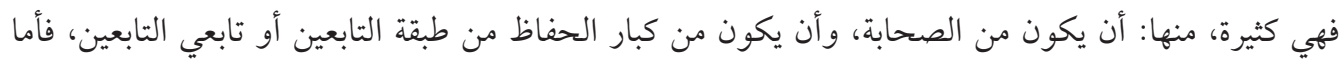

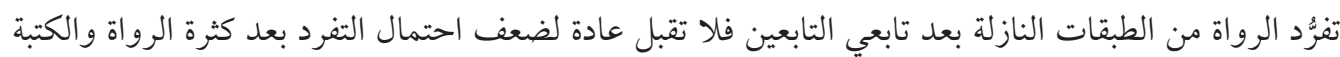
والحفاظ.

فهذا هو منهج المحدثين في المسألة، وأما الحنفية فلهم نظر آخر فيها، فإنهم يعملونها على جميع الرواة

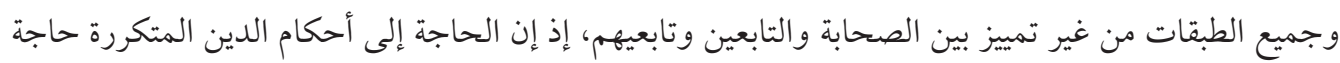

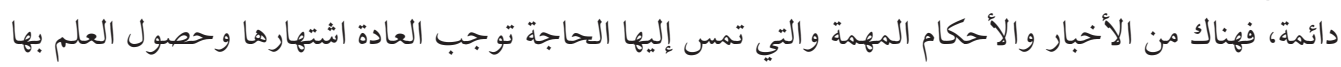

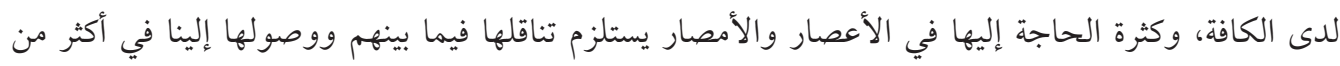
طريق، ويستلزم الشك بها إن جاءت من طريق الحة إلها في الاعطار والادمار.

ويستبعد القول بسكوت الصحابة عن نقل الرواية لصدورها عن بعضهم بسبب تفرقهم في الأمصار، فمسائل عموم البلوى هي من المسائل التي توجد الحاجة إليها في مصر والشام وأفريقية والحجاز وسائر بلاد المسلمين. وأنتقل بعد بيان حدود المسألة إلى تأصيلها وتحريرها عند الحنفية في المباحث الآتية.

\section{المبحث الأول: رأي الحنفية في عموم البلوى، بناؤها والاستدلال لها}

بعد الكلام عن تعريف المسألة وملابساتها، نتتقل إلى عرض المسألة كما أراد لها الحنفية المتقدمون. اتفق الأصوليون الحنفية والمتكلمون على نسبة هذه المسألة إلى الحنفية، وخرجو المليها عددًا من المسائل،

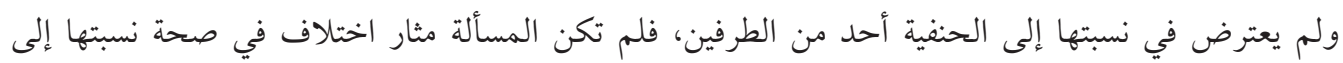

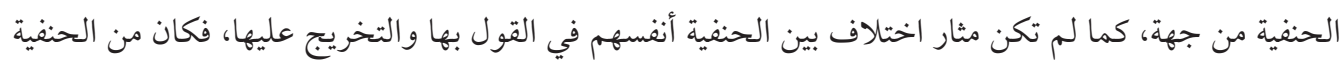

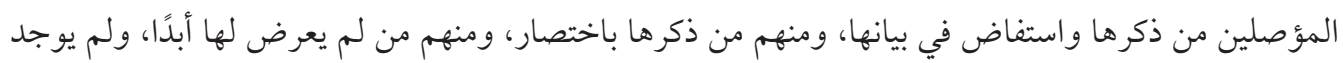

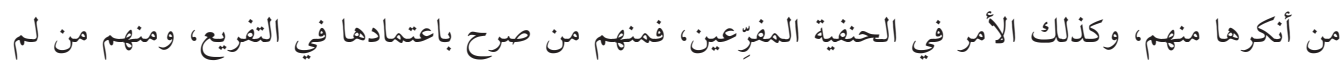
يصرح، وإن كان الجميع قد اتفقوا على القول بنتائجها.

9

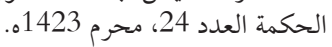




\section{المطلب الأول: أقدم إيراد للفظ عند الحنفية المتقدمين}

ورد لفظ (اعموم البلوى) كثيرًا في كتب الحنفية كما عند غيرهم من الأصوليين، وأرادوا منها أمرين، الأول:

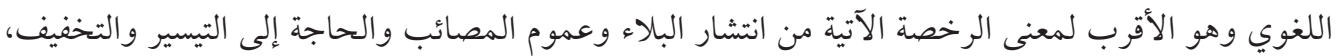
وقد عرَّفه السرخسي بقوله: وصف مؤثر في الحكم إلى جهة التهن التخفيف. 10

و الثاني وهو المعنى الأصولي الحديثي لدى الحنفية الذي سبق بيانه، وقد ورد المعنيان معًا في كتب الحنب الحنفية

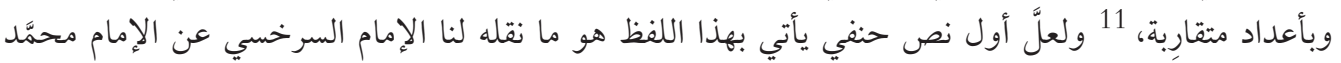

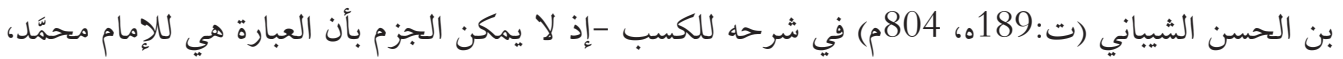

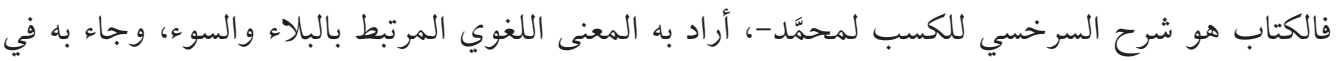

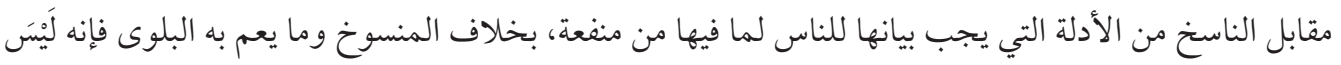

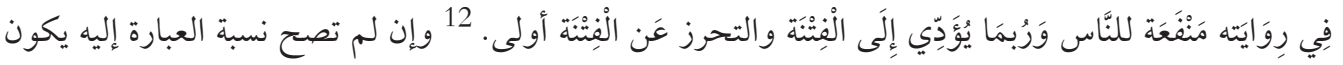

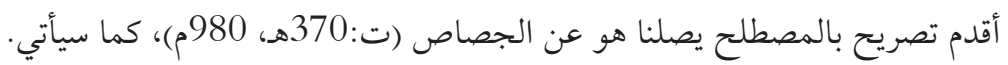

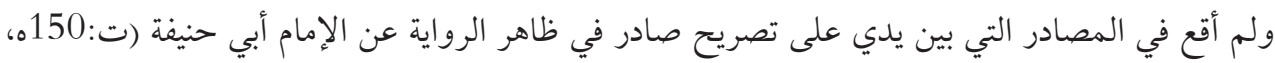

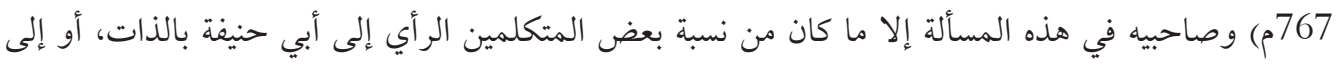

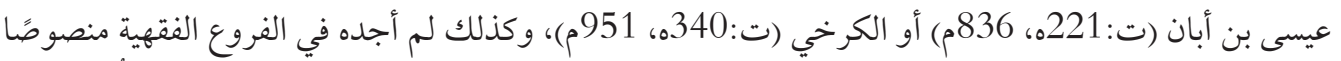

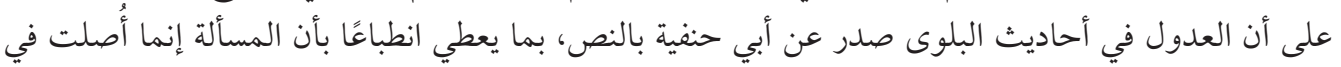

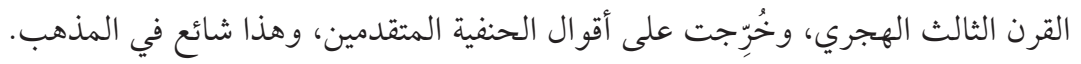
ولكن حمل بعض متأخري الحنفية أقوالاً وأحكامًا وردت في ظاهر الرواية على عموم البلوى، ومنه مسألة

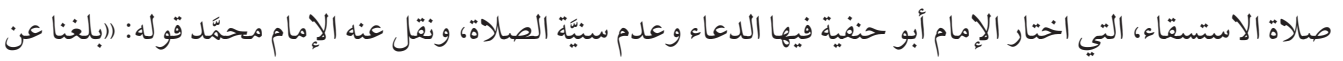

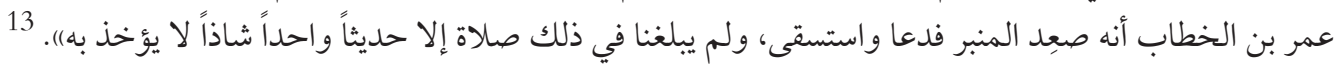
فنقل ابن مازة (ت:616ه، 1219م) العبارة، وذكر في تفسير الشذوذ فيها قولين، فقال: (اختلفت النقلة

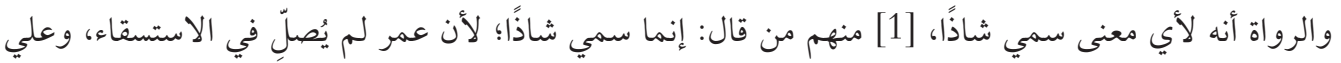

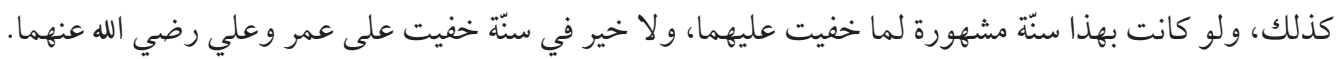

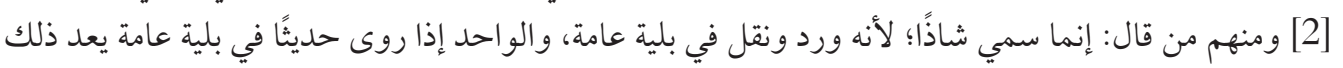

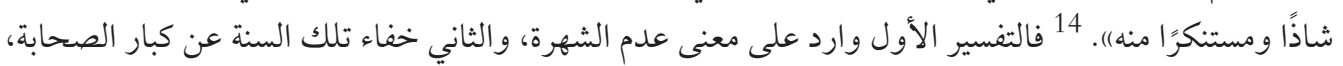

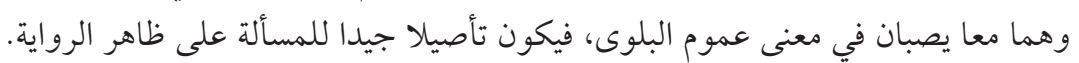

$$
\text { 10 } 10
$$

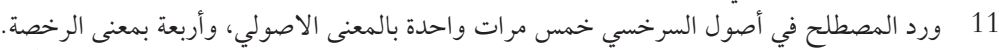

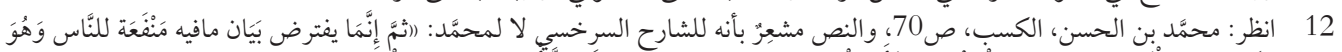

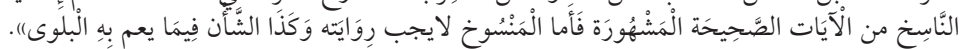

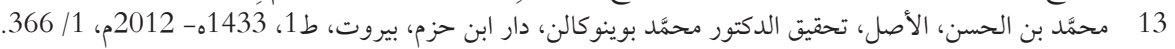
14 
وكذلك فعل ابن الهمام (ت: 861ه، 1457م) إذ إنه أورد المسألة بعبارته فقال: و الحديث الوارد فيها (اشَاذٌّ

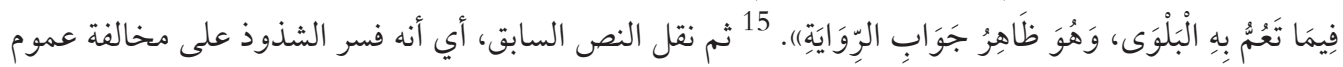

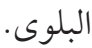

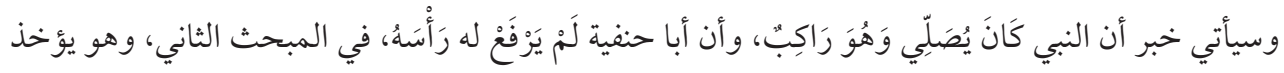

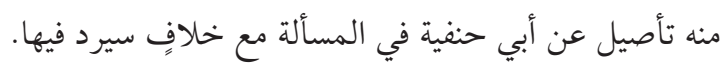

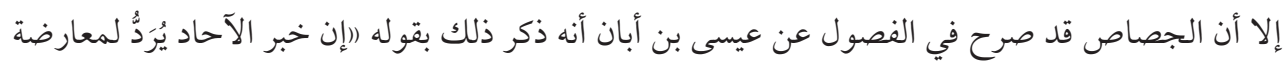

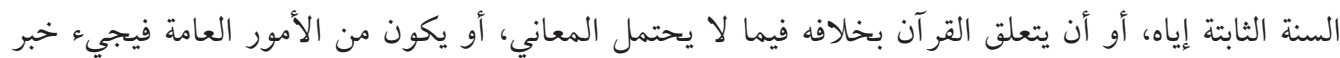

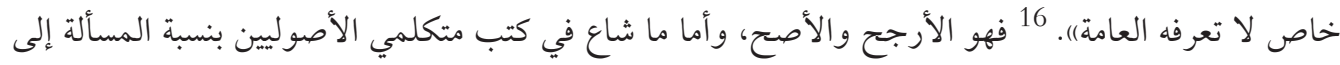

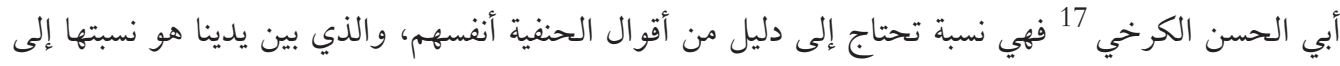

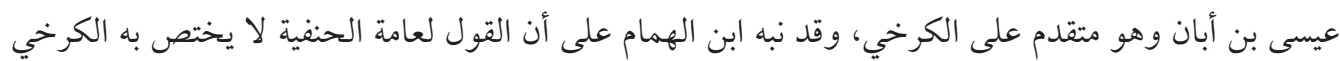
كما توهم بعضهم، كما حققه أمير بادشاه. 18

\section{المطلب الثاني: إيراد مسألة عموم البلوى في كتب متقدمي الحنفية}

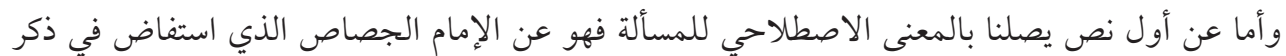

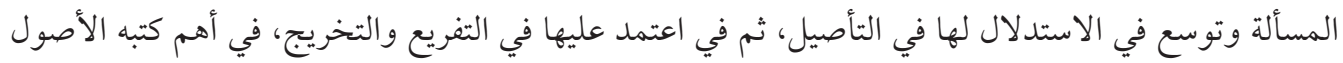

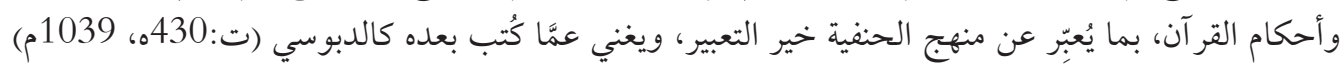

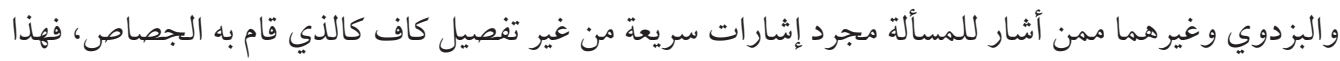
سبب التركيز على هذا الإمام. 19

\section{أبو بكر أحمد بن علي الرَّازي الجصَّاص، تأصيل المسألة والتدليل عليها}

للمسألة حضور خاص عند الإمام الجصاص، إذ أوردها في كتبه الأصولية والفقهية، فتوسع في التأصيل

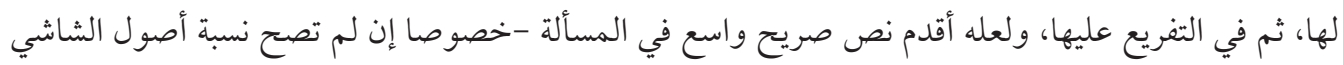

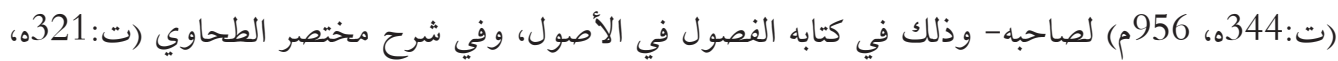

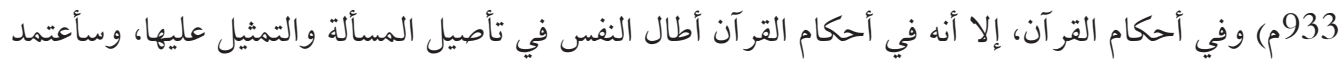

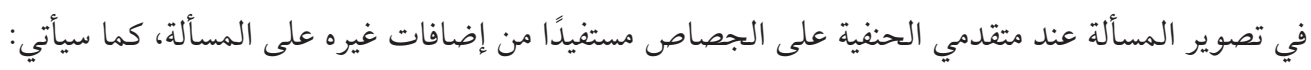
15

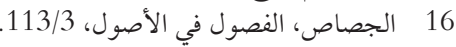

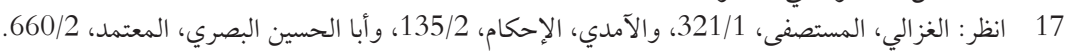

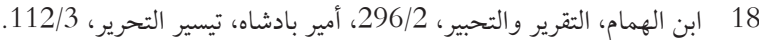

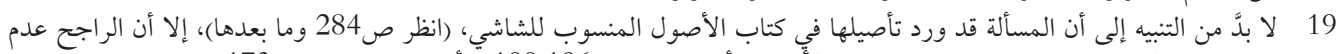

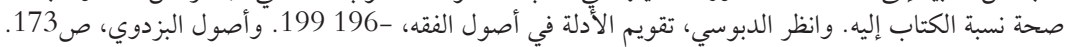




\section{أ- توصيف القول بعموم البلوى}

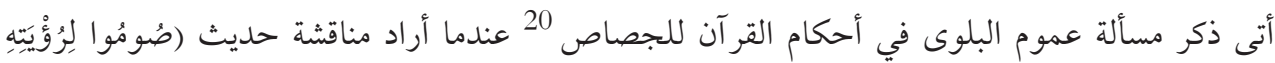

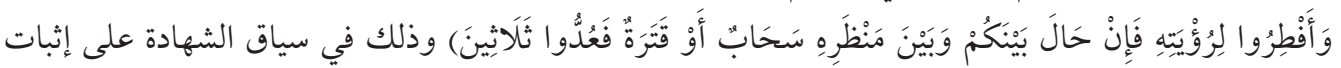

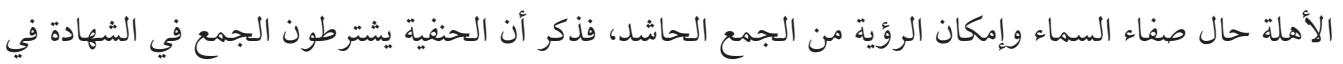

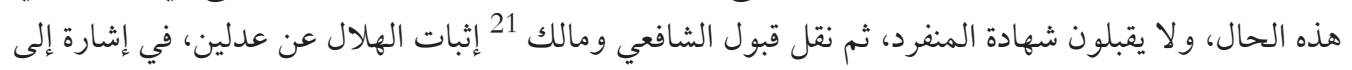

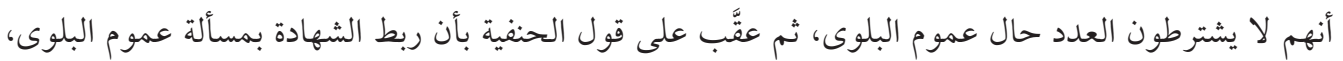

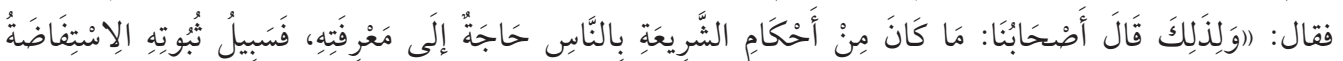

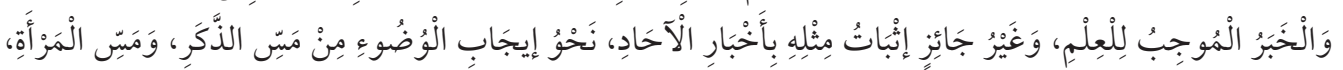

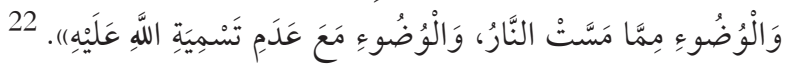

وللجصاص أهمية أخرى في المسألة في كونه أقدم مصدر يتوسع في المسألة ويستدل عليها بالأدلة العقلية

والنقلية، كما سيأتي.

\section{ب- الأدلة العقلية والثقلية على القول بعموم البلوى أولاً: الأدلة العقلية}

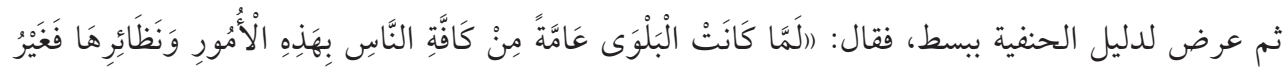

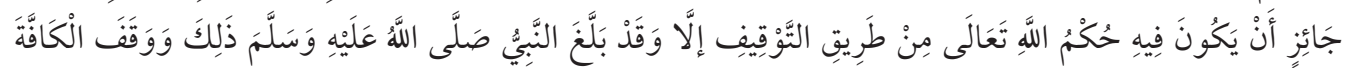

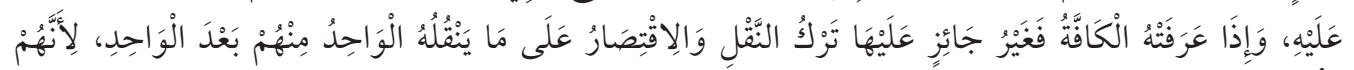

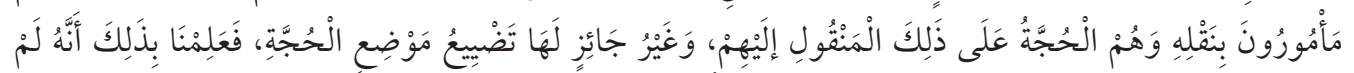

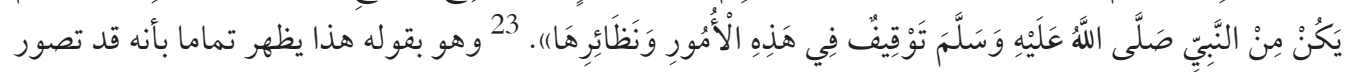

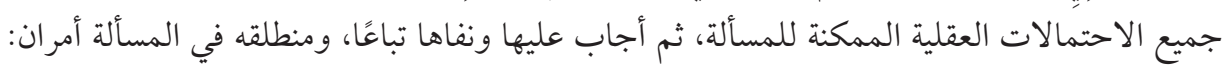
1 - حاجة الجميع إلى معرفة هذا الحكم، ووجوب سؤالهم أهل الذكر في هذه الأحكام الضرورية. 2 - ووجوب التبليغ على النبي صلى الله عليه وسلم أولاً، ثم على من سمع منه البلاغ، حتى ولو لم يُسأل عنه.

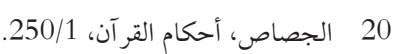
21 سيأتي أن المالكية هم أقرب المذآن المب إلى الحنفية في مسألة عموم البلوى، بالتصريح أو بالتطبيق، واقتضى هذا التوضيح أن الجصاص

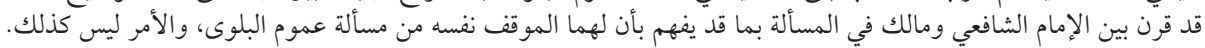

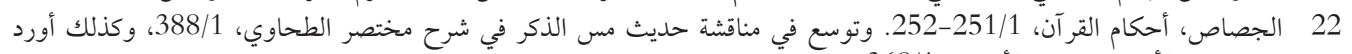

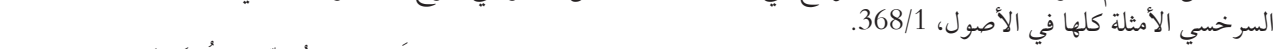

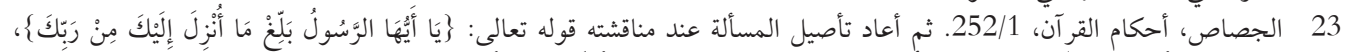
الجصاص، أحكام القر آن، 106/4. وتأصيلها عند السرخسي قريب منه أيضًا، انظر أصوله، 368/1. 


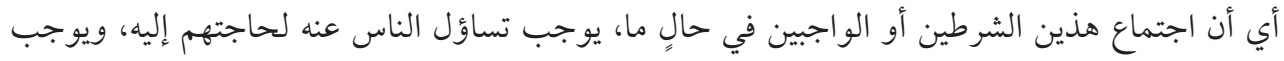
تبليغ العارف به للكافة حوله، وعندها يكون التفرد في نقل خبرٍ منها داخلاً فيما سماه الشاشي: بمخالفة الظاهر،

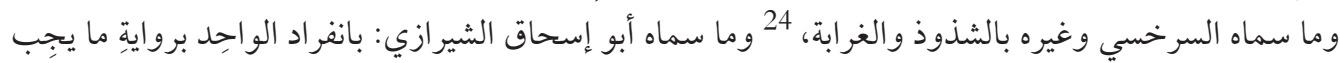
على الكَّافَّة عِلمُه. 25 وهي أدق تسمية و أكثرها وضوحِّا في التعبير عن منهج الحنفية من عموم البلوى.

\section{ثانيًا: الأدلة الثقلية من السنة وعمل الصحابة}

وأما عن تأصيل عموم البلوى في النَّقل، فإن الجصاص يتوقف عند ذلك في الفصول في الأصول، بعد أن

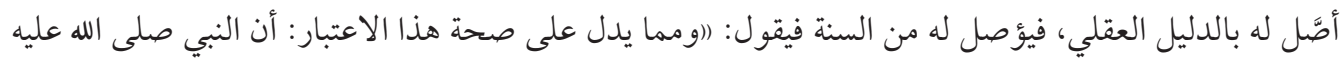
وسلم لم يقتصر على خبر ذي اليدين في قوله: (أقصرت الصلاة أم نسيت حتى سأل أبا بكر وعمر - رضي الله

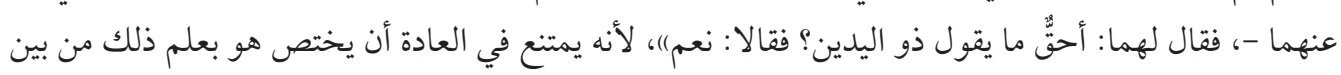

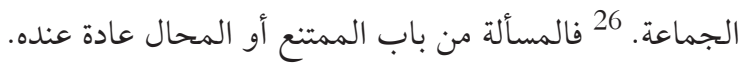

كذلك يؤصل له من فعل عمر بن الخطاب من الصحابة، فيقول: (وأما رد عمر لخبر أبي موسى الأشعري

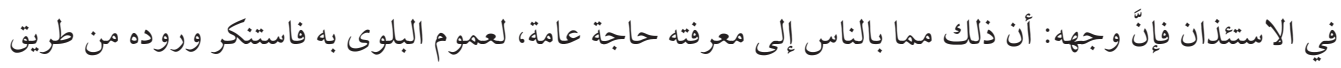
الآحاد، وهذا عندنا إحدى العلل التي يرد بها أخبار الآحاد على نحو ما ذكرنا في رؤية الهالاله). 27 ولئن اعتُرض على الحنفية في الحديث بأن استنكار عمر قد جبرته شهادة أبي سعيد وهو خبر آحاد لا يصل إلى الشهرة، فالجواب هو إنما كان جابر حديث أبي موسى هو الصحابة الذين كانوا في المجلس جميعًا، وهم

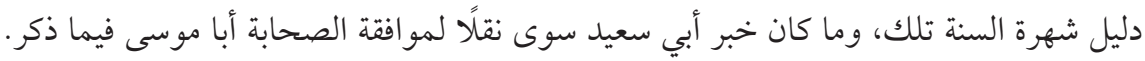

\section{المبحث الثاني: ضوابط القول بعموم البلوى، وأسباب العدول عن الحديث لأجله}

لا يفهم مما سبق أن الحنفية يأخذون بقاعدة عموم البلوى على إطلاقها، بل إن لهم فيها تدقيقا وحدودا وضو ابط، بعضها مستمدُ من صريح كلامهم في كتب الأصول، ومعظمها مستنبط من صنيعهم في كتب الفروع. وبعضها مما اتفقوا عليه، و أكثرها مما نص عليه بعضهم. فلا بدَّ من ذكرها و التنبيه عليها. كذا إنه قد ذُكر للمسألة أسباب ومقومات، يأتي تفصيلها تباعا.

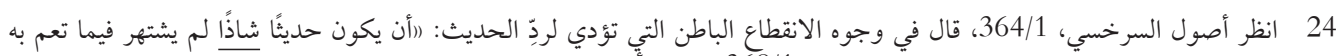

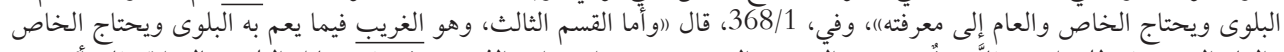

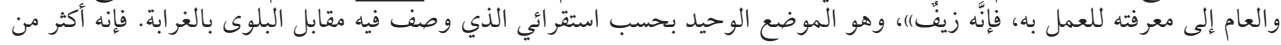

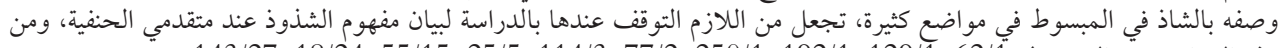

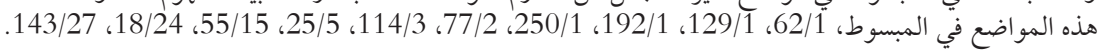
25 26 الجصاص، الفصول في الأصول 115/3. 27 الجصاص، الفصول في الأصول، 107/3. 


\title{
المطلب الأول: حدود عموم البلوى عند الحنفية، وقيودها
}

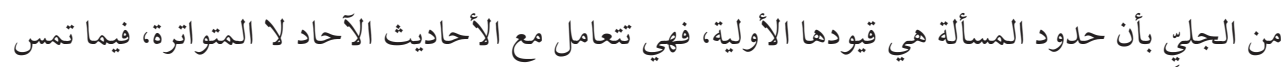

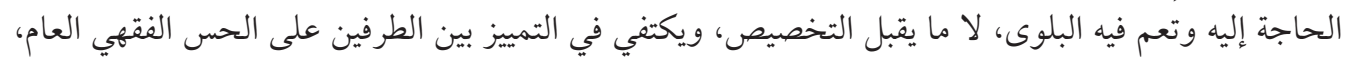

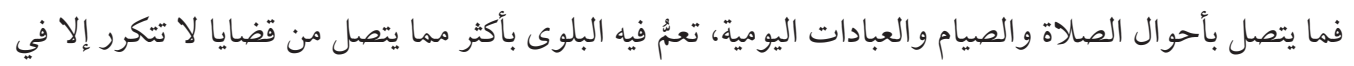

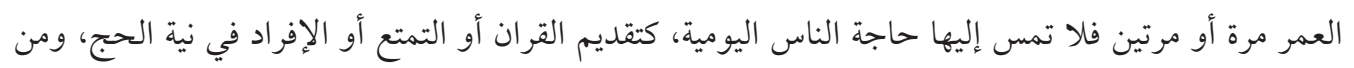

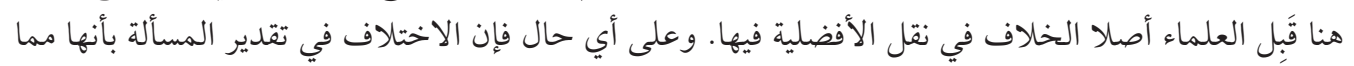

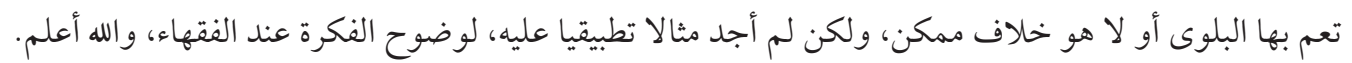

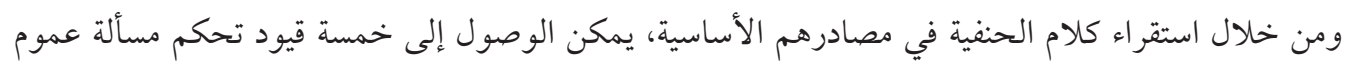
البلوى عندهم، بعضها متفق عليه، وبعضها جرى فيه بعض النغ النقاش بين الحنفية كما سيأتي.

\section{القيد الأول: المسألة مفترضة فيما صح سنده من أحاديث}

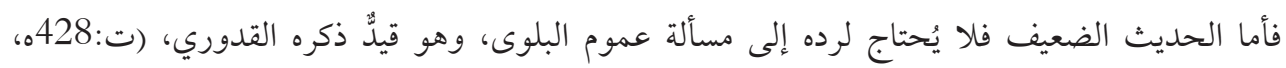

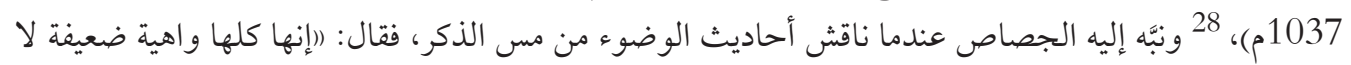

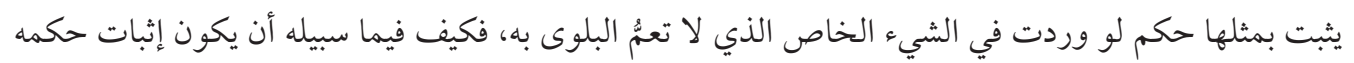
من جهة التواتر؟) 29

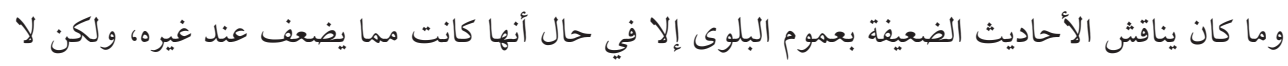

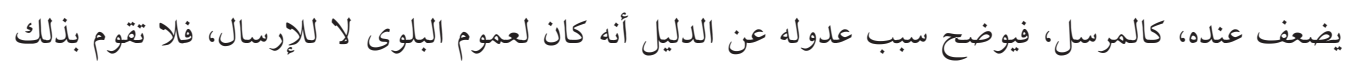
حجة عليه.

\section{القيد الثاني: المسألة مفترضة في الأحاديث الآحاد، التي لم تشتهر ولم يجر عليها العمل}

بهذا يكون نطاق البحث في الحديث الآحاد الذي تفرد فيه الراوي بذكر حكمٍ من نوع ما يجب على الفي الكافة

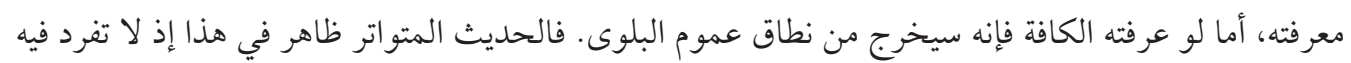

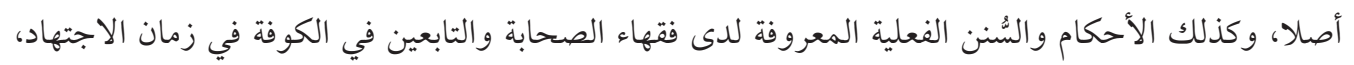

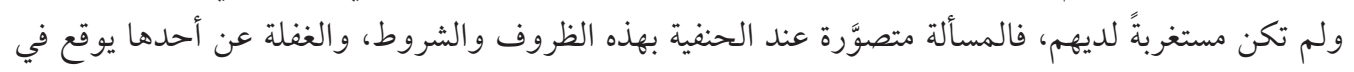
سوء الفهم عنهم.

\author{
28 2 القدوري، التجريد، 190/1. \\ 29 الجصاص، شرح مختصر الطحاوي، 301/1/ 30 \\ 30 الجصاص، شرح مختصر الطحاوي، 1/-392 399.
}


فالمقصود إذن هو الحديث الذي وصل إلينا برواية الآحاد عن الآحاد حتى وصل إلى مداره كذلك، وليس

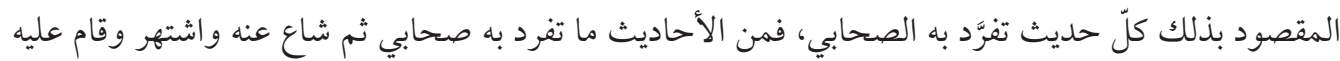

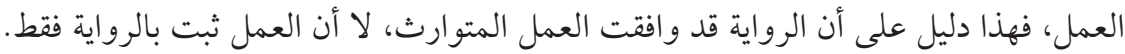

ويشبه ذلك أن يعتر صلى على الحديث بأن بعض الصحابة لم يعلم به، فهذا لا يخل باشتهاره، ويقبله الحنفية،

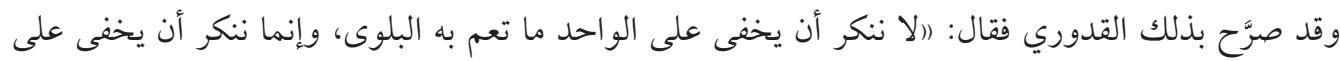

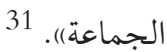

وبذلك ناقش الجصاص مسألة أخذ الحنفية بحديث حمنة بن جحش في أقلّ مدَّة الحيض، 32 واستخدم

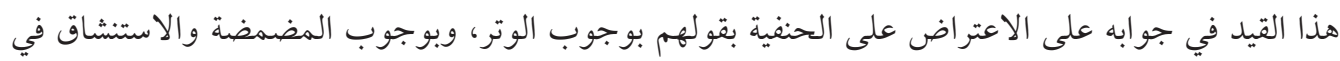

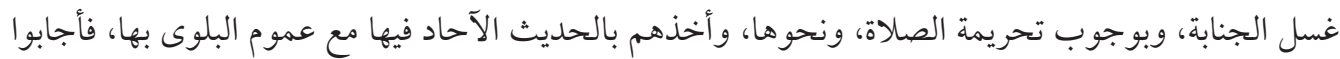

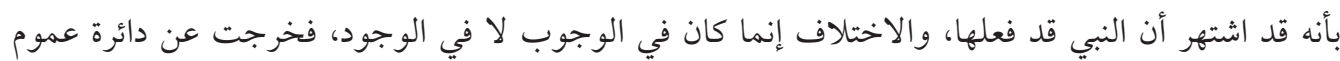

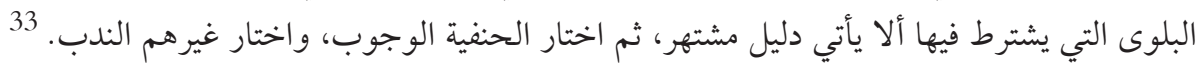

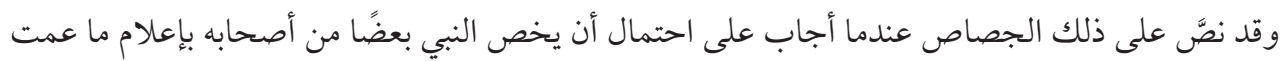

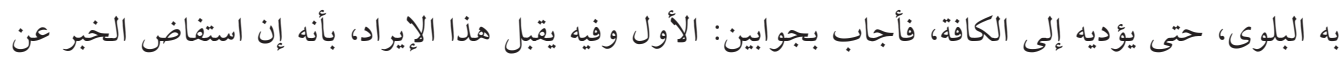

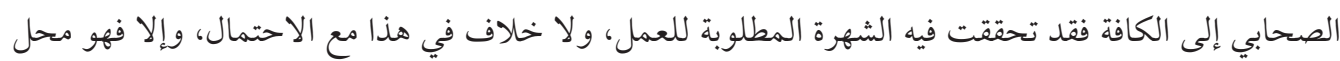

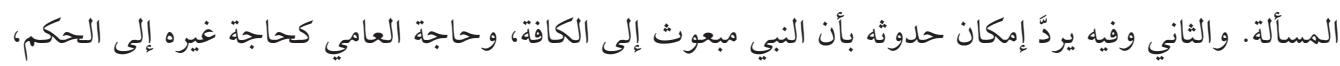
فلا بد من توقيف الجماعة على الحكم، وإلا فهو ليس من عموم البلوى أصلاً. ومن هنا يُستشكل أن طرفًا ليس بالقليل من اعتراضات المتكلمين على الحنفية في المسألة قد وقعت في

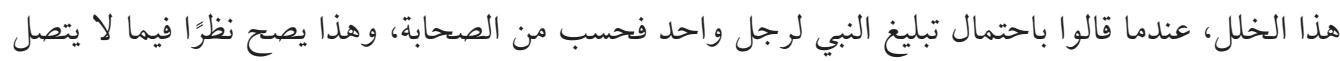

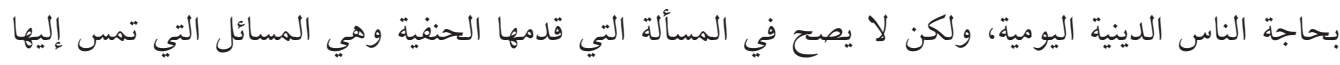

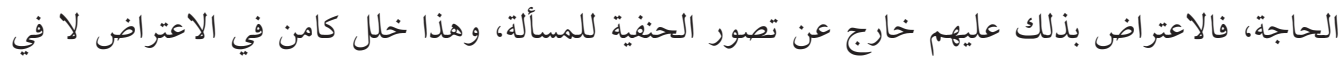

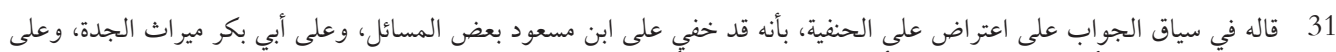

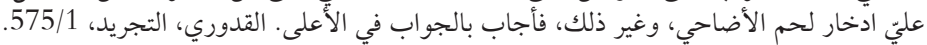

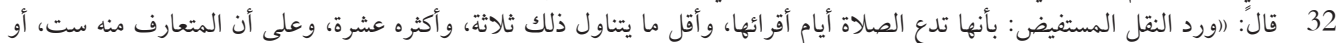

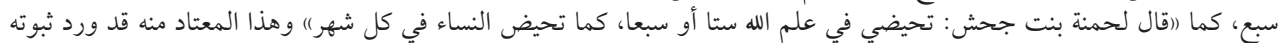

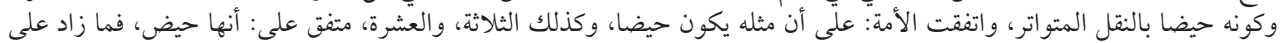

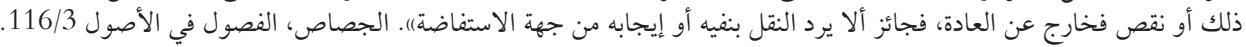

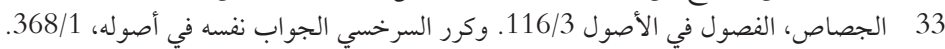

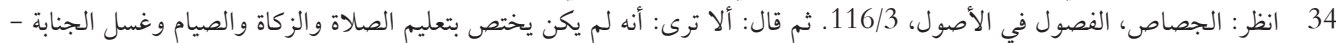

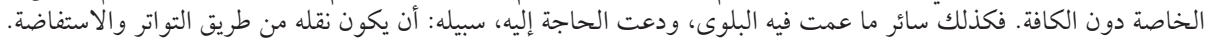

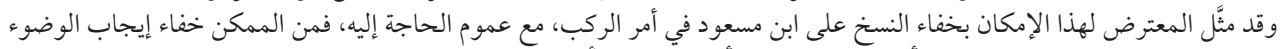

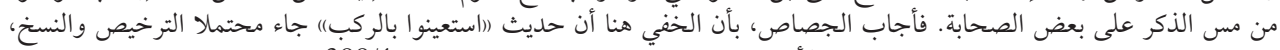

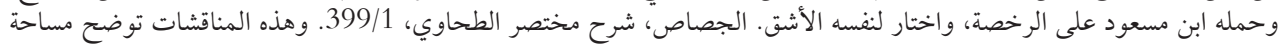
الحرية في تناول الموضوع بين الفقهاء. 
وكذلك اعتر اضهم بأن الحكم قد ينقله راوٍ أو صحابيّي واحدٌ ثم يشتهر عنه، ويسكت البقية عن التبليغ لتحقق

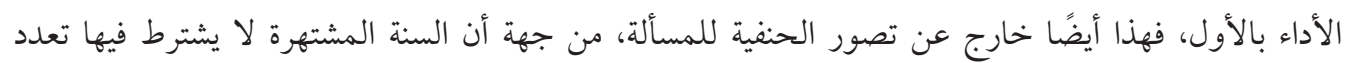

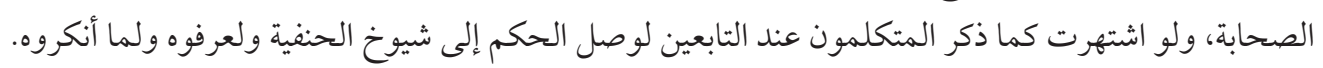

\section{القيد الثالث: المسألة مفترضة بالراوي الذي ليس له مزية خاصة تؤهله لسماع هذا الحديث بنفسه}

بحيث يكون واسطة التبليغ عن النبي إلى سائر المسلمين وذلك لقربه الشديد من النبي أو لحصول واقعة النقا

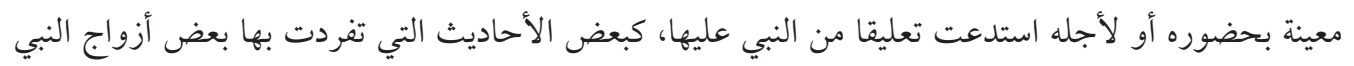

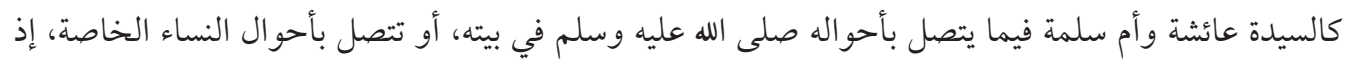

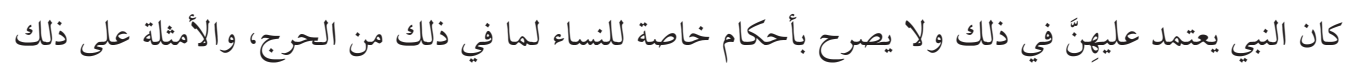

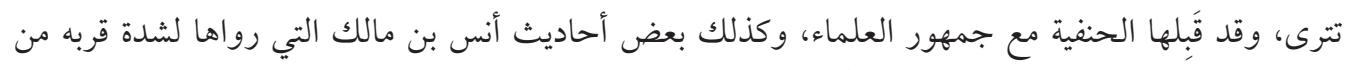
النبي وخدمته له أثناء مكثه في المدينة. 35

\section{القيد الرابع: المسألة مختصة بالأحاديث التي يؤخذ منها أحكام الفرائض

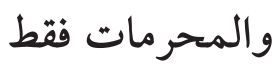

لا السنن والمستحبات، وهو مفهوم من كون الفرائض هي مجال السؤال والحاجة، وكونها مجال تعميم

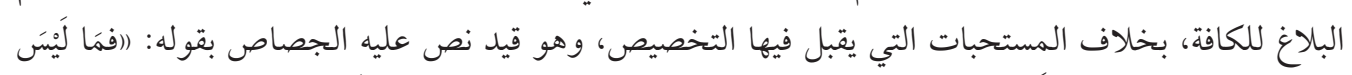

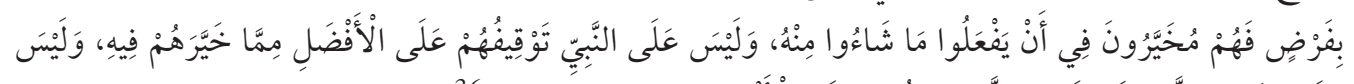

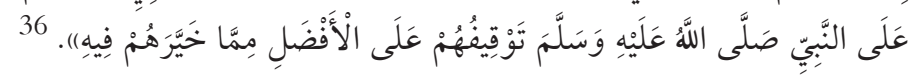

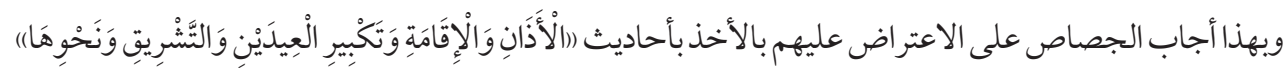

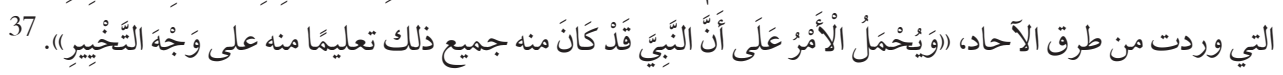

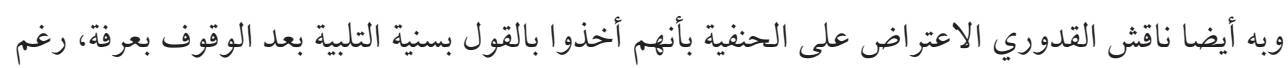

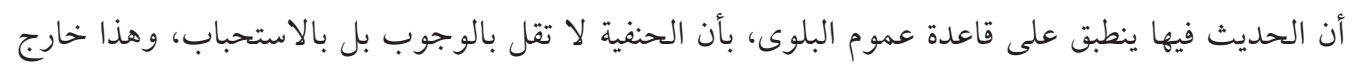

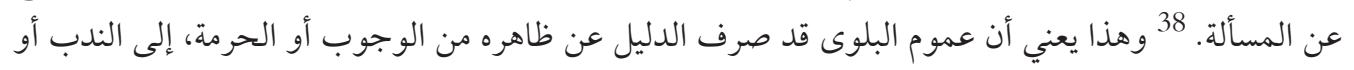

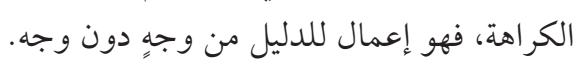

$$
\begin{aligned}
& 35 \text { انظر الشيباني، الأصل، 333/1. والعيني، البناية شرح الهداية، دار الكتب العلمية، بيروت، ط1، 1420ه، 629/1. }
\end{aligned}
$$

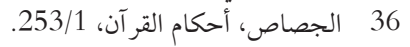

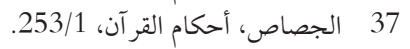

$$
\begin{aligned}
& 38 \text { القدوري، التجريد، 796/2. }
\end{aligned}
$$


ومن هنا يترجح لدينا أن ما ذكره البزدوي 39 تمثيلا على المسألة بحديث (الجهر بالتسمية)) وهو أصلا في

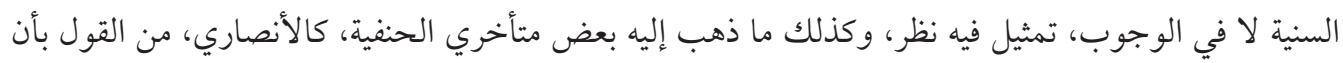

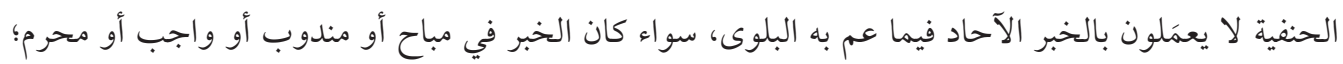

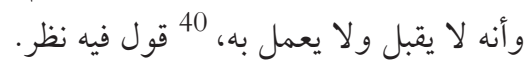

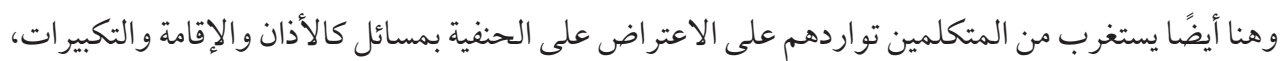

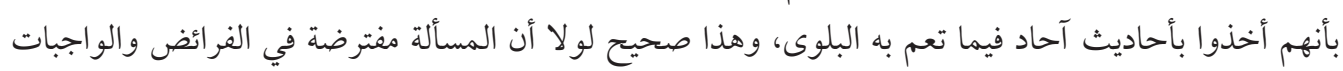

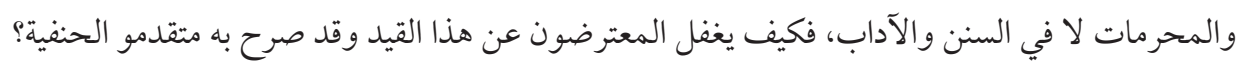

\section{القيد الخامس: مخالفة الحديث لخبر آخر}

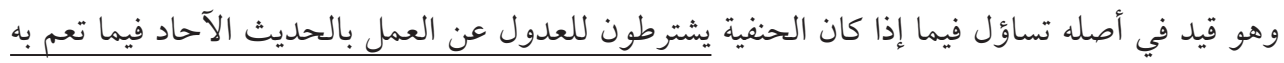

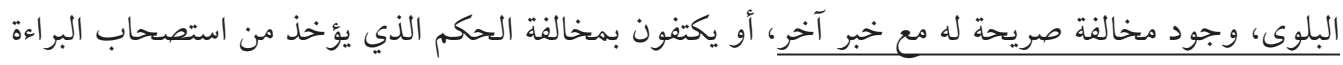

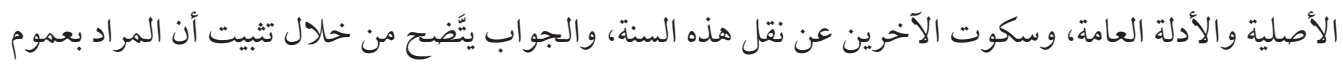

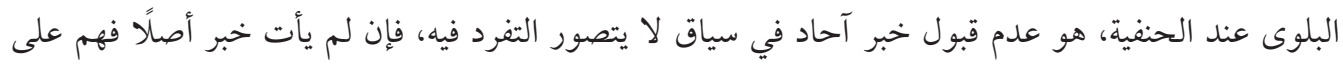

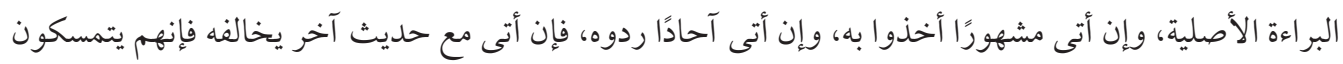

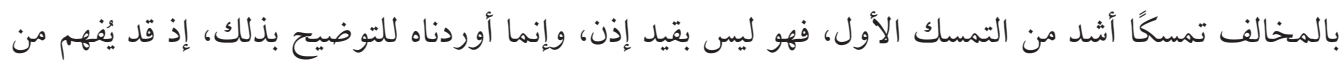
صنيعهم عندما يوردون الدليل المعارِض له. له.

وبعبارة أخرى فإن السكوت إذن كاف للقول بعموم البلوى لدى الحنفية، فإن جاءت المخالفة الصريحة

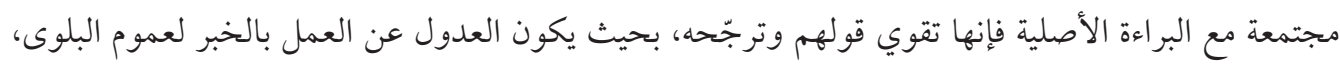

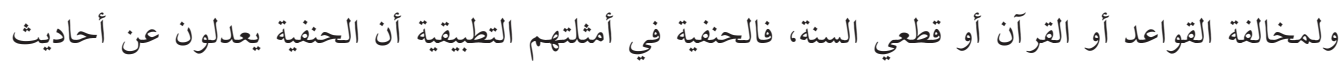

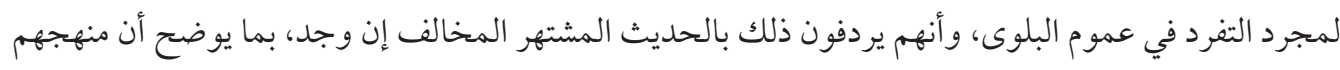

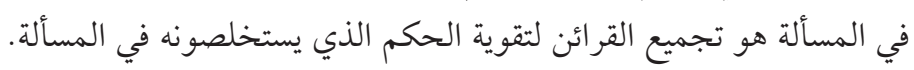

\section{المطلب الثاني: أسباب رد الحديث بعموم البلوى وسياقها

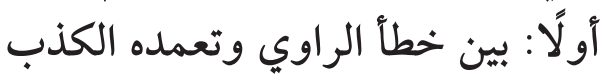

لا بلَّ من التبيه إلى مسألة متصلة بما سبق، وقد حصل فيها اللبس أيضا على الحنفية، وهي أنهم إنما

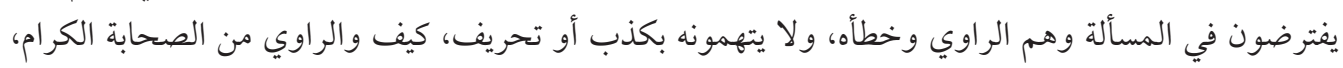

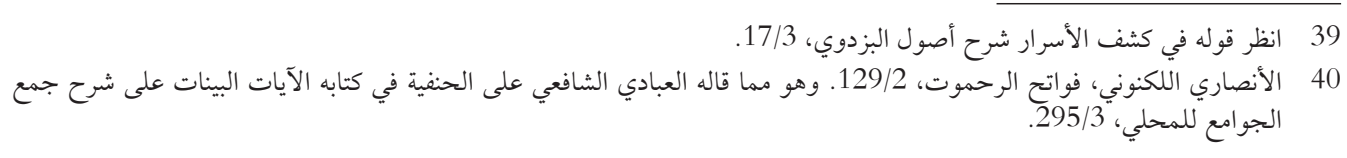


وهذا صريح في النصوص التي أوردها الجصاص و الشاشي والسرخسي وغيرهم من المتقدمين الذين ما جاؤوا

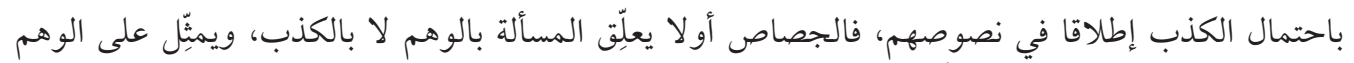

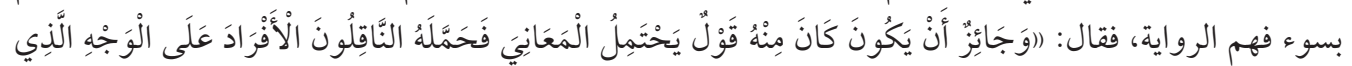

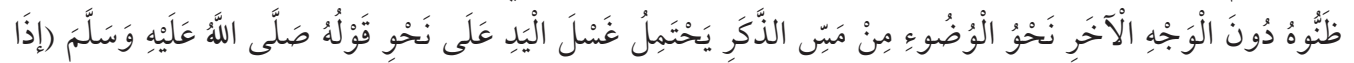

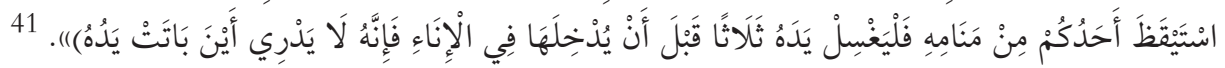

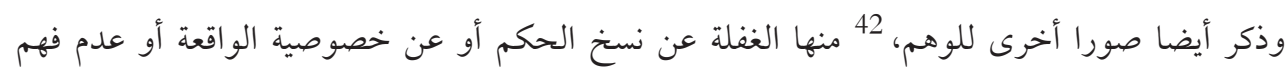

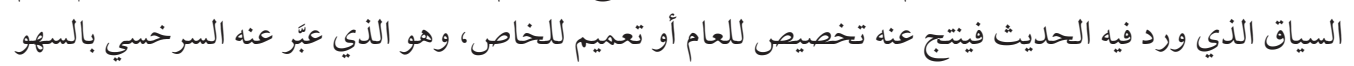
أو النسخ، 43 وغير ذلك من الأوهام.

وعلى أي حال فإن عبارة الجصاص في المسألة جاءت أكثر دقة من عبارة السرخسي الذي عبَّر عن الحديث

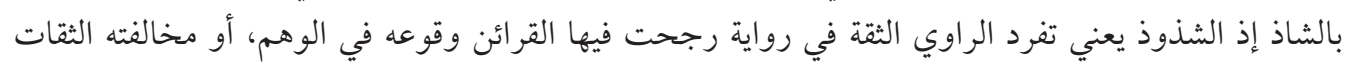

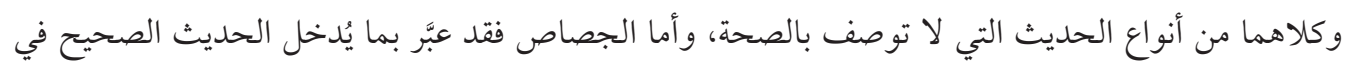

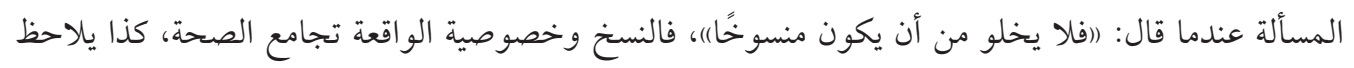

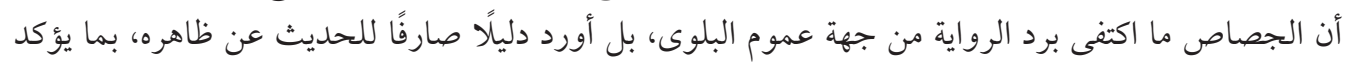

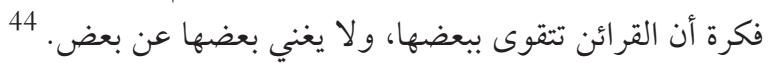

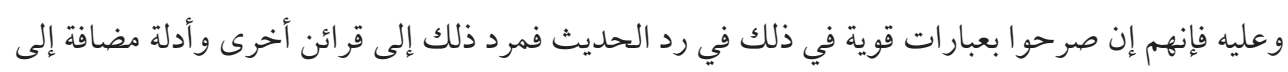

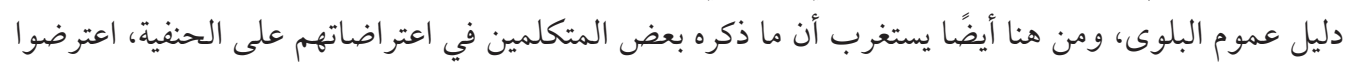

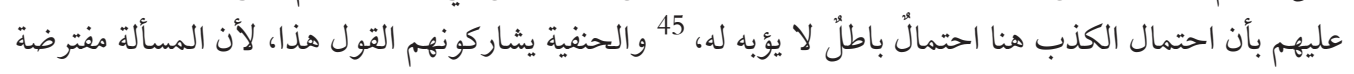

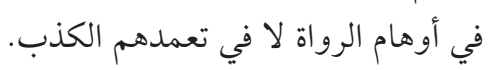

\section{ثانيا: بين كون المسألة من القواعد المستقرة أو من القرائن النسبية}

الفارق جليّ بين القاعدة والقرينة في التوظيف والاستدلال، وأهم مزايا القاعدة استقرارها وثبوتها، وأنها

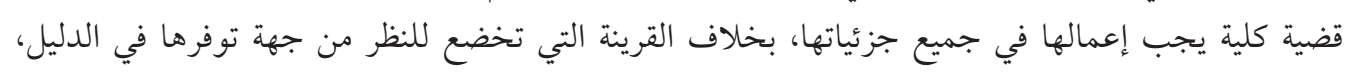

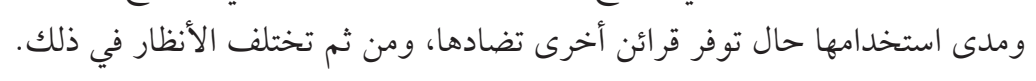

$$
\begin{aligned}
& 41 \text { الجصاص، أحكام القرآن، 1/-251 } 252 . \\
& 42 \text { الجصاص، الفصول في الأصول، 115/3. } \\
& 43
\end{aligned}
$$

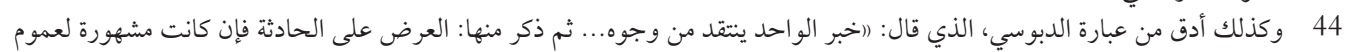

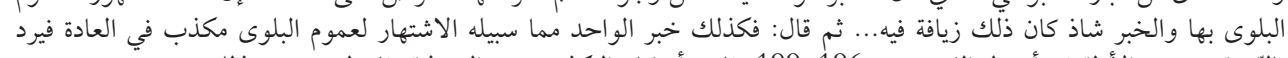

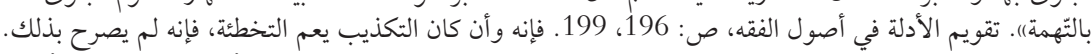

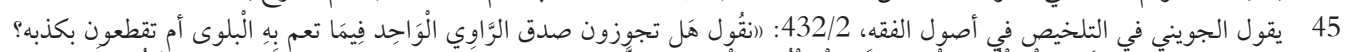

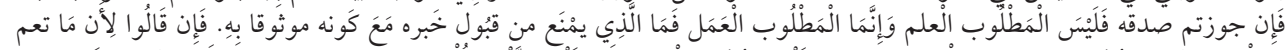

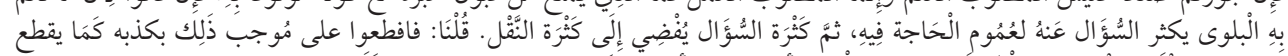

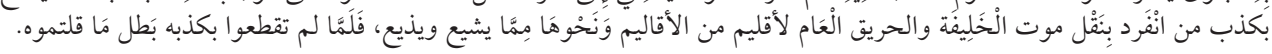


ولتحديد مسألة عموم البلوى فيما إذا تنتسب لطائفة القواعد أو القرائن يجب البحث في تأصيل أو تطبيق

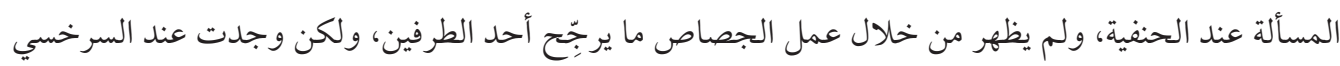

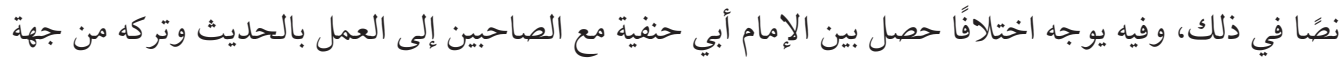
عموم البلوى، وتوضيحه فيما يأتي:

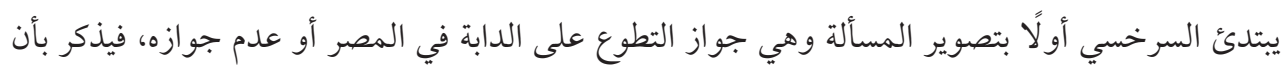

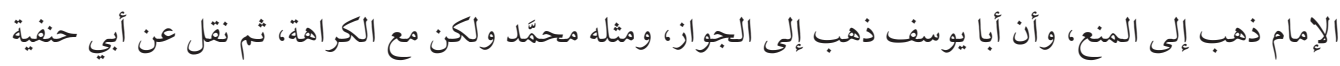

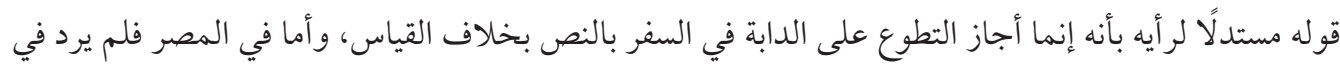

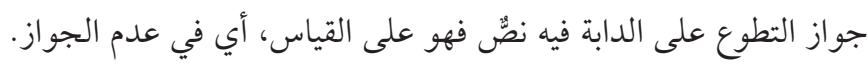

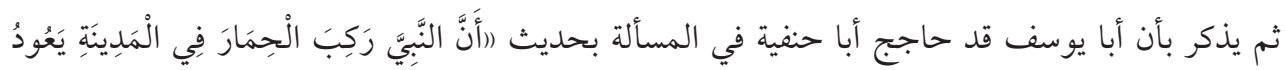

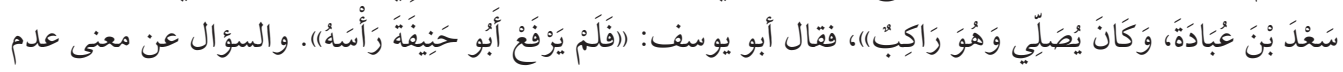

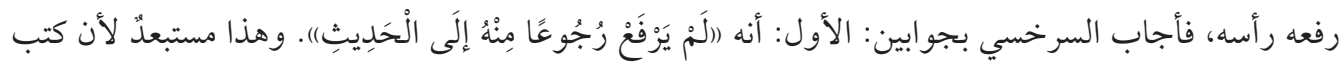

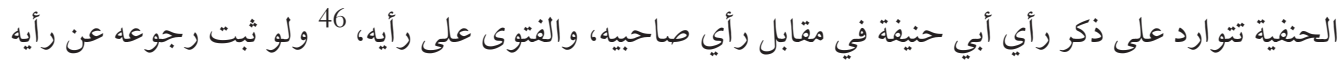
لما صحَّ استقرار الفتوى على قوله.

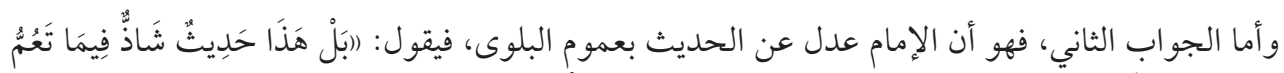

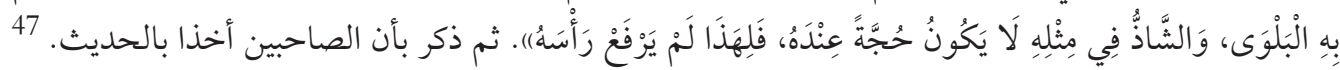

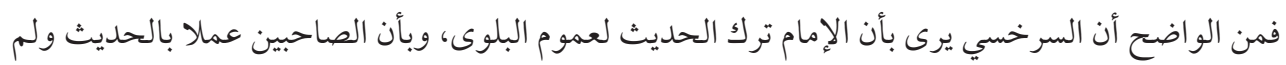

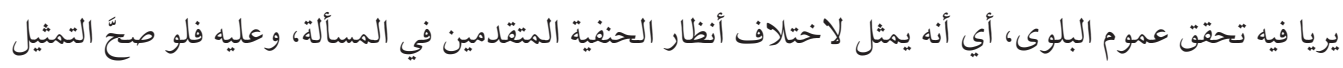

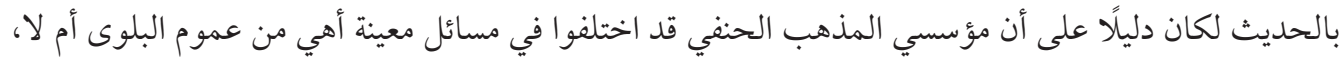

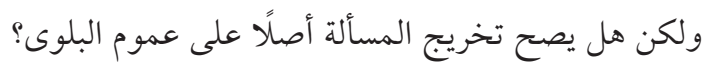

الذي يظهر لديَّ هو أن الإمام عدل عن الحديث في المسألة، لأنه رأى أن مخالفة القياس -وهو هنا القواعد

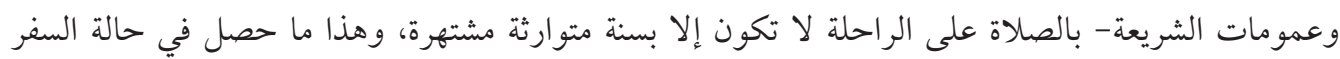

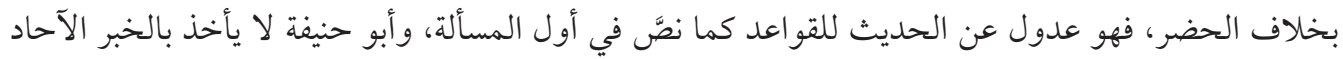
عند مخالفة القواعد.

وليست المسألة خاضعة لعموم البلوى، لأن الركوب في المصر على قلَّهَ لا يكون لزمن كافِ للصلاة بل

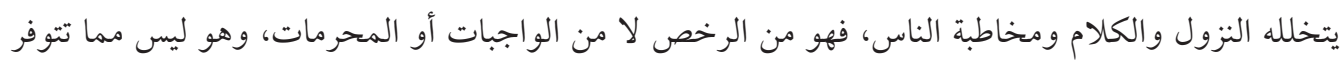

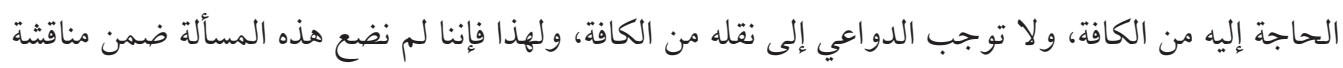

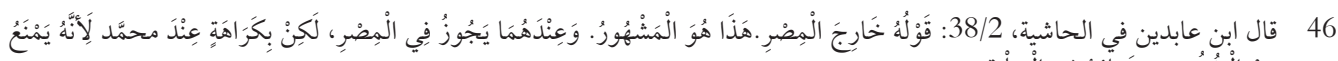

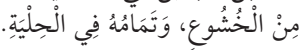
السرخسي، المبسوط، 250/1. 
أقدم إيراد لمسألة عموم البلوى عند الحنفية، إذ لو صح الاستدلال منها، لكانت نصا عن الإمام أبي حنيفة فيها. والله أعلم.

وأما بخصوص مسألة صلاة الاستسقاء، ومخالفة الصاحبين أبا حنيفة فيها، وعملهما بالحديث في صلاة

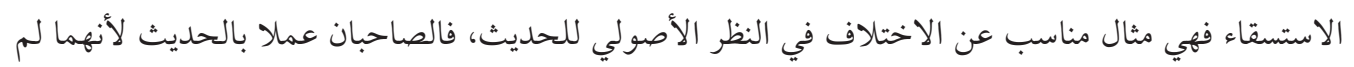

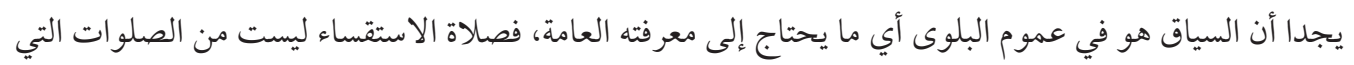

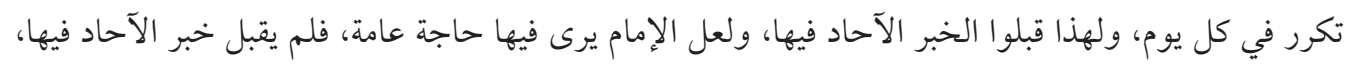

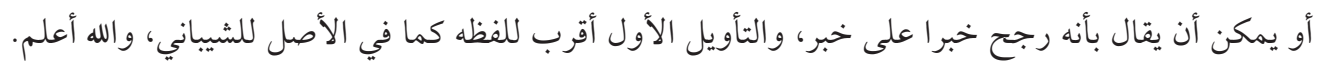
وعليه فلا يتوفر بين يدي مثال يظهر العمل بالحديث مع القيود الخمسة السابقة رغم عموم البلوى، بما يشير

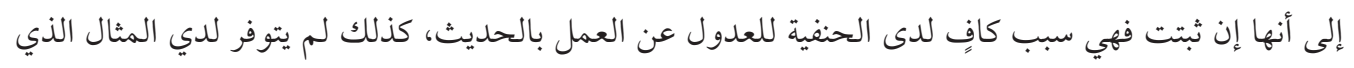

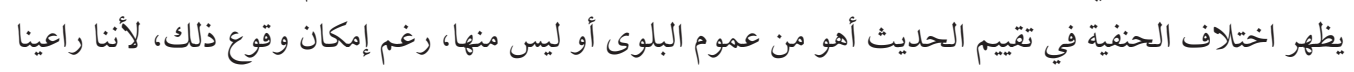

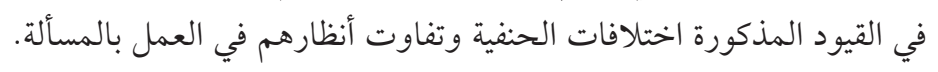

وإن اعتُرض على الحنفية بقولهم بنقض الوضوء بالفصد والحجامة بأنه حديث فرد ضعيف في عموم

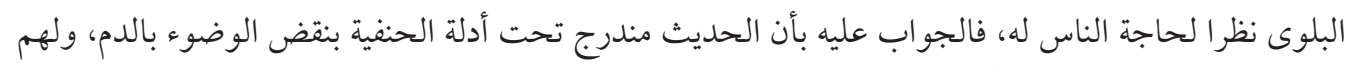

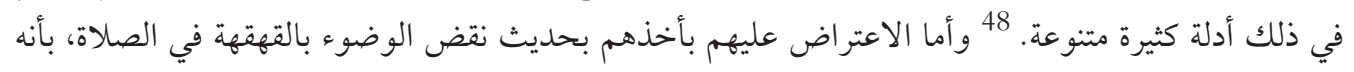

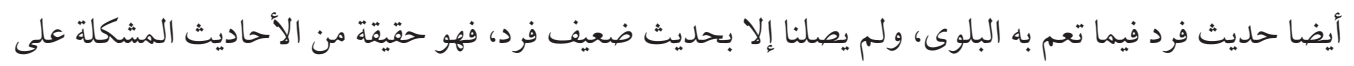

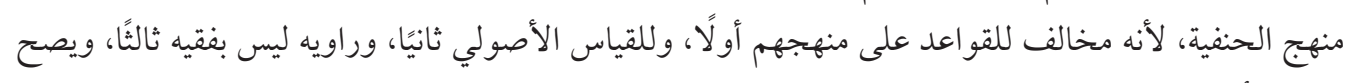

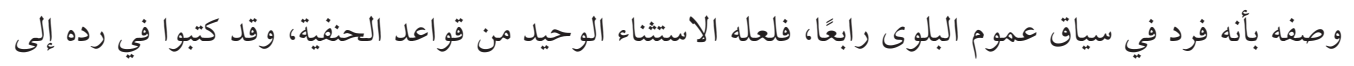

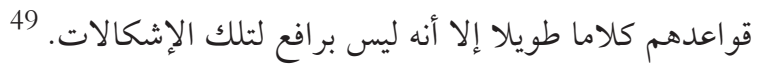

ولهزا فإني أختار في الجواب عليه ما ذكره البخاري، بقوله (الأصلُ فيما عم به البلوى اشتهارُ حكمه لما لمال

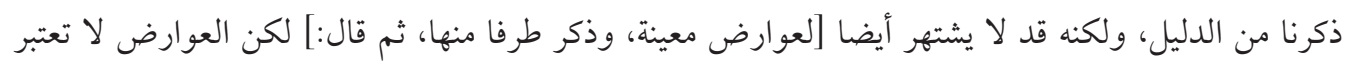

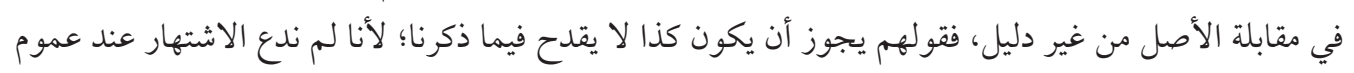

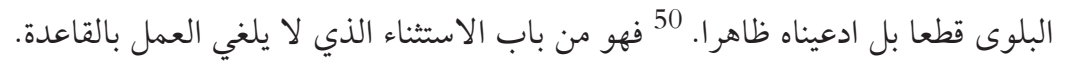

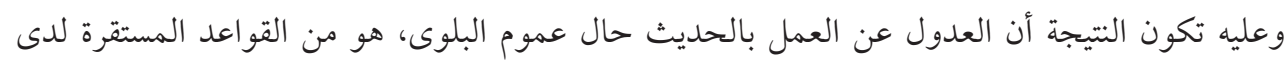

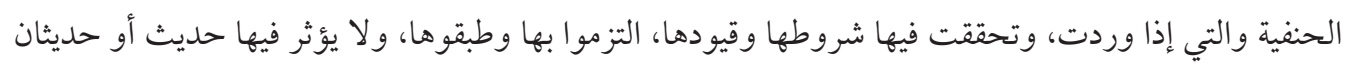

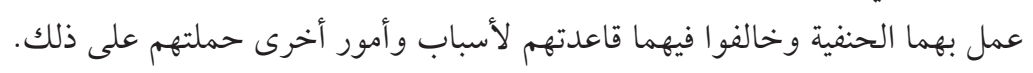

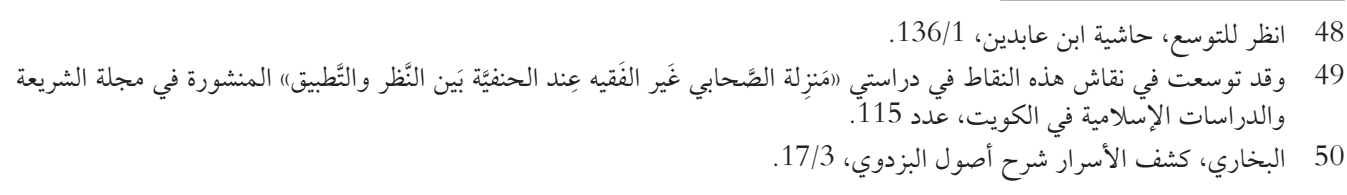




\section{المبحث الثالث: التوظيف الفقهي العملي لعموم البلوى عند الحنفية وغيرهم}

أكتفي بذكر أهم المسائل التي أوردها الجصاص والقدوري والسرخسي من متقدمي شيوخ الحنفية لقاعدة

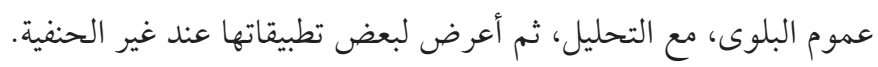

\section{أولا: خرَّج الجصاص على القاعدة، المسائل الآتية:}

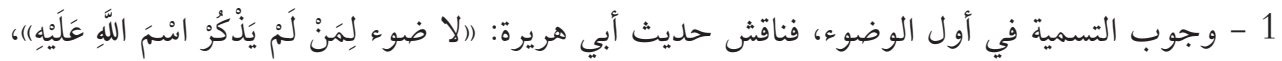

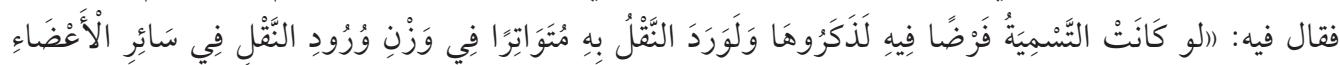

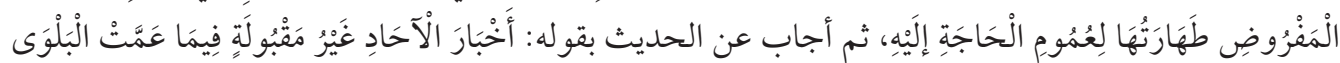

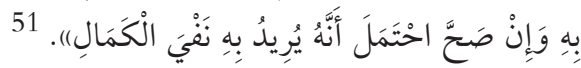

ذكره الجصاص، ويُشكل في عبارته أنه أتى بلفظ التواتر وهو ليس بشرط كما صرَّح هو في التأصيل.

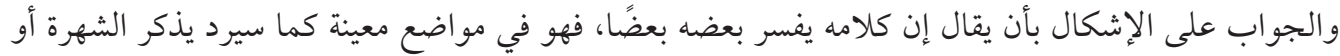

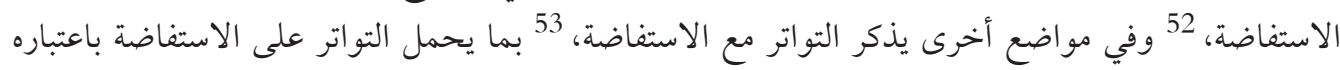

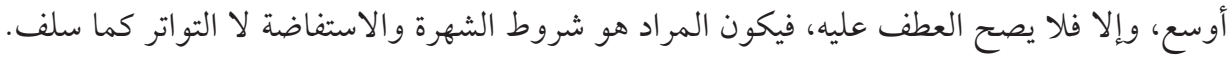

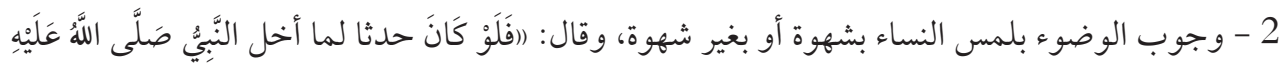

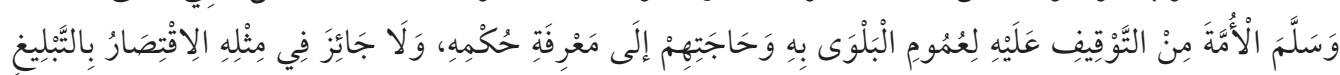

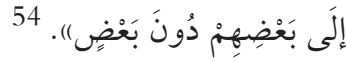

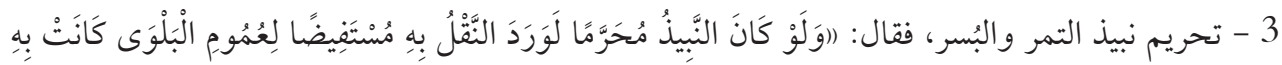

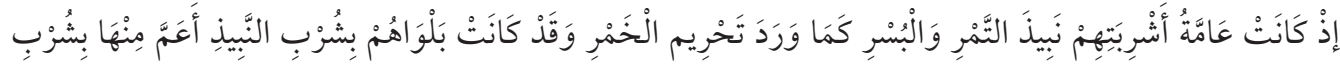

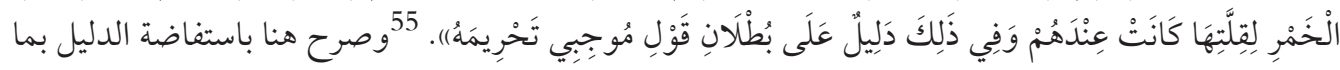
يشير إلى توارد المصطلحين على المحل ذاته عند متقدمي الحنفية، الشهرة والاستفاضة.

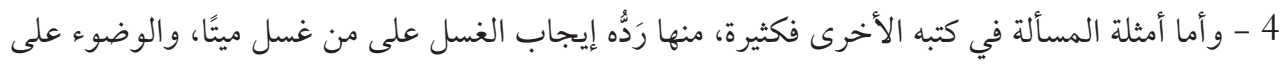

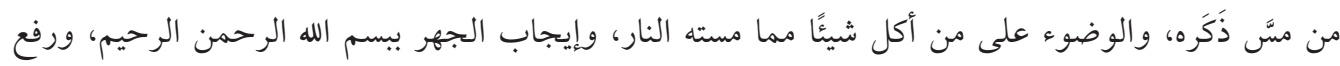

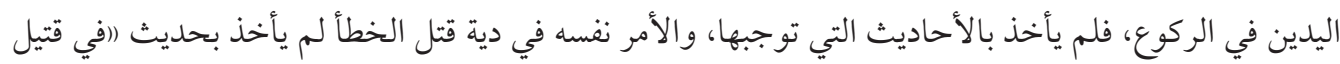

$$
\begin{aligned}
& 51
\end{aligned}
$$

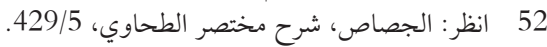

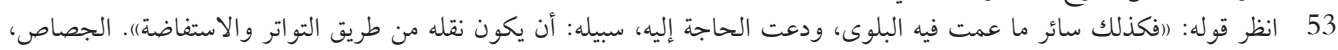

$$
\begin{aligned}
& \text { الفصول في الأصول، 116/3. } \\
& 54 \\
& 55
\end{aligned}
$$


خطأ العمد: أربعون منها خَلِفَة في بطونها أو لادها)، 56، 57 وكان يعقِبِ مناقشتها بقوله: لو كانت هذه الأمور ثابتة لنقلها الكافة.

\section{ثانيا: خرَّج القدوري عليها المسائل الآثية}

5 - فلم يعمل بحديث أبي أيوب ((وليستنج بثلاث أحجار))، لأنه خبر واحد، فلا يثبت ما تعم به البلوى

على أصولنا.

6 - ولا بحديث بُسرة بنت صفوان (إذا مس أحدكم ذكره فليتوضاً)،، ونقل عن سعيد بن منصور قوله: حديث بسرة لا يساوي بعرة. ثم قال: (فهذا طعن الأئمة عليه، وخبر الواحد لو سلم من الطعن لم يقبل عندنا فيما تعم به البلوى، فمع الطعن أولى").

7 - وناقش أدلة إثبات حُرمة المدينة فقال: (هذه أخبار آحاد، و إثبات الحرم أمر تعم به البلوى، فلا بدَّ أن يبينه النبي بيانًا عامَّا، ولو فعل ذلك لنقل سبب البيان، فلما لم ينقل إلا من جهة الآحاد لم يجز إثبات التحريم بهاب.

8 - وناقش أدلة وجوب الختان، وردها بأنها من أخبار الآحاد، وقال: (هذا مما تعم به البلوى به، فكان

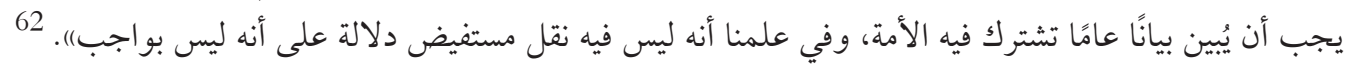

\section{ثالثا: خرَّج السرخسي عليها المسائل الآتية}

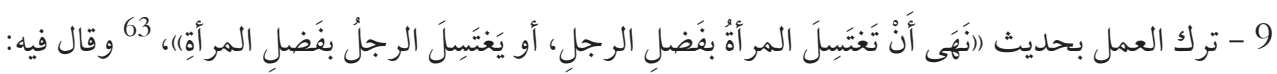

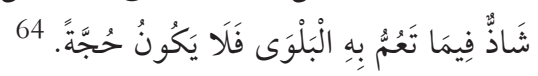

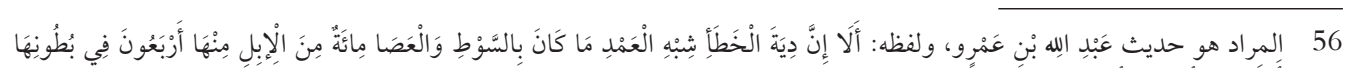

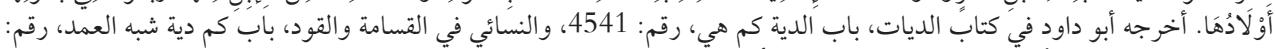

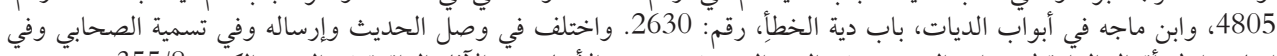

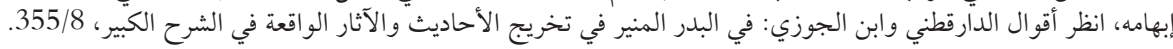

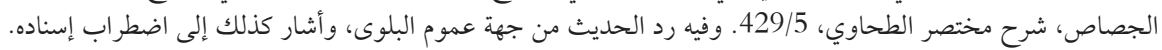

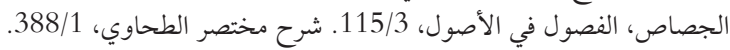
59 القدوري، التجريد، 58

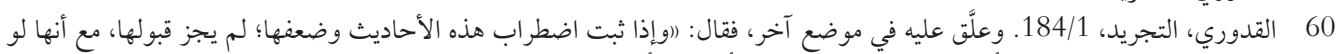

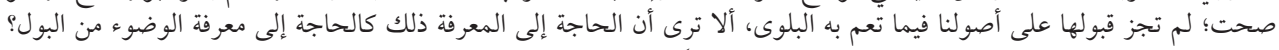

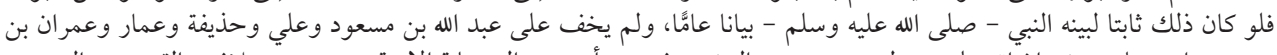

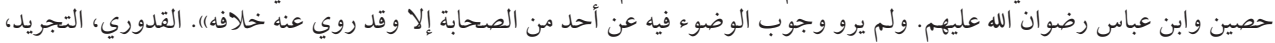

190/1

$$
61 \text { 62 القدوري، التجريد، } 63 \text { التدوري، التجريد، 6120/12. }
$$

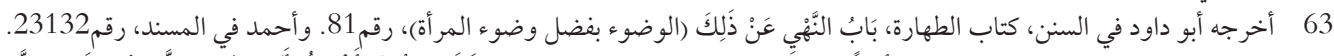

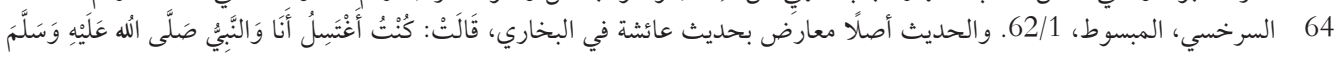




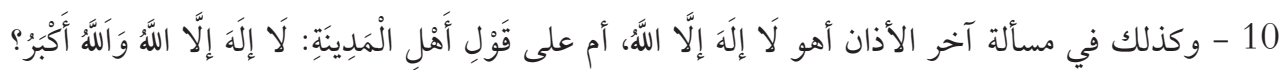

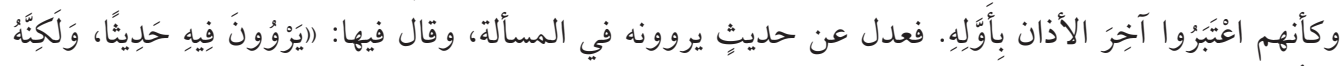

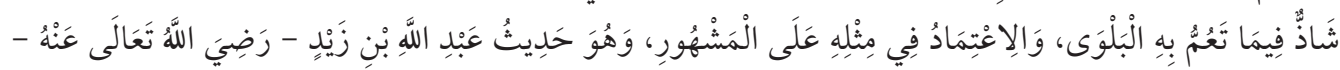

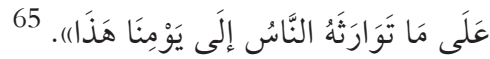

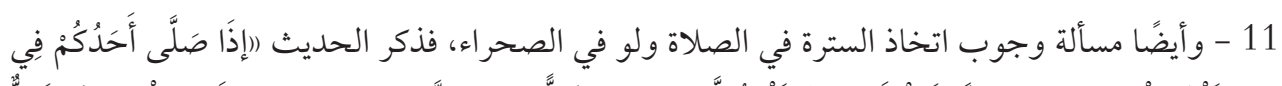

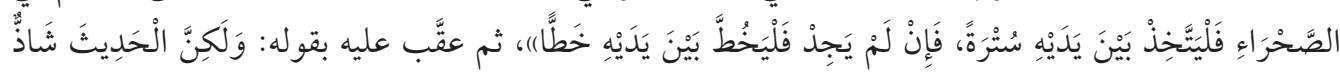

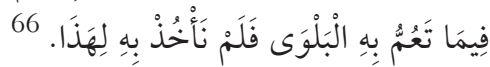

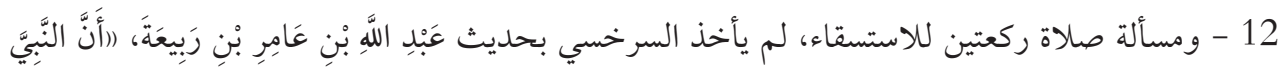

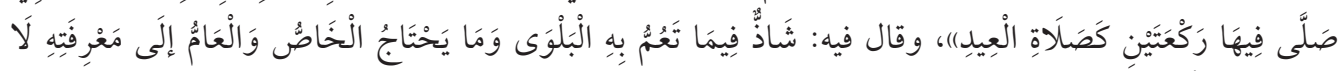

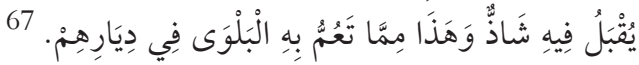

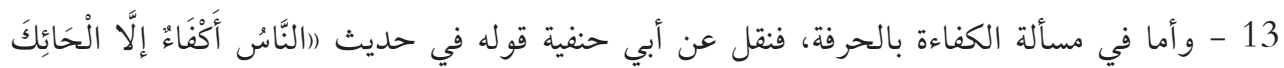

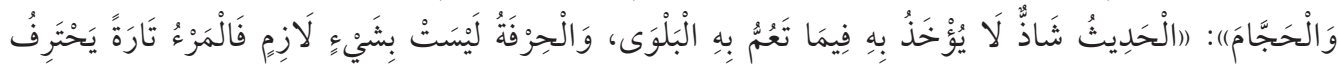

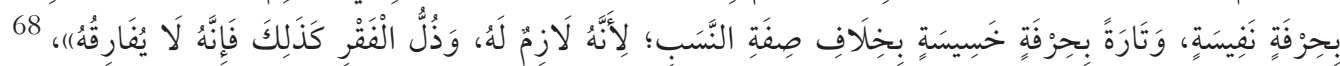

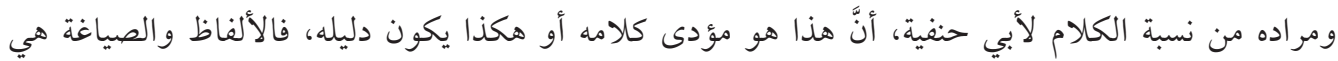
للسرخسي.

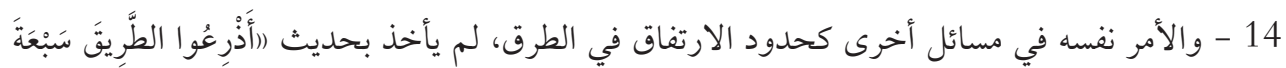

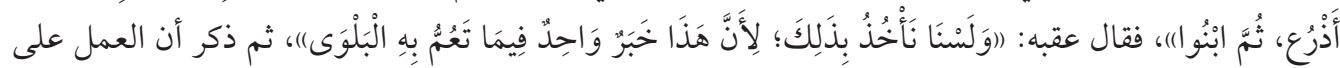

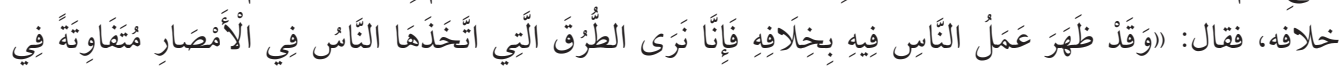

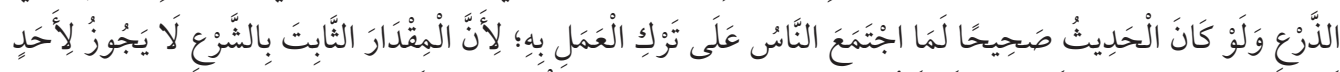

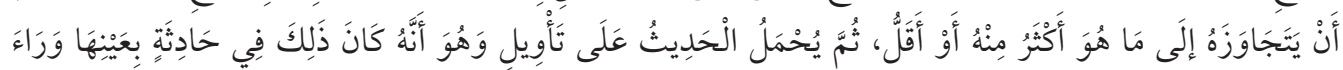

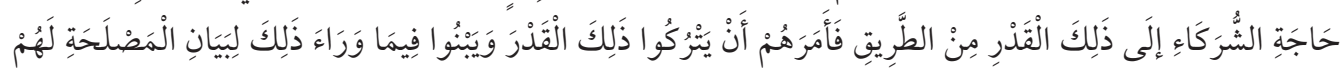

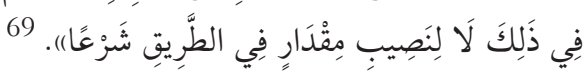

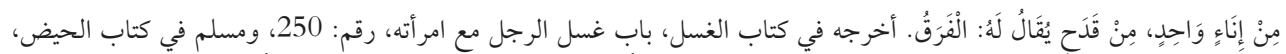

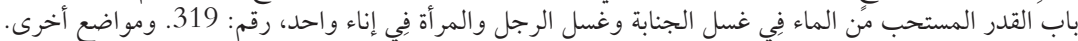
65

66

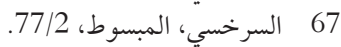

68 68 68

69 السرخسي، المبسوط، 55/15.
} 


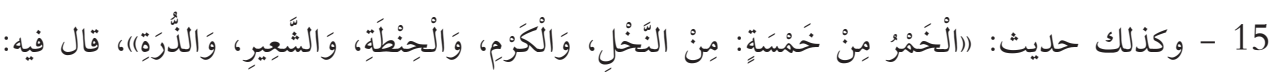

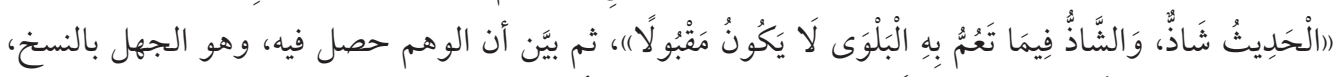

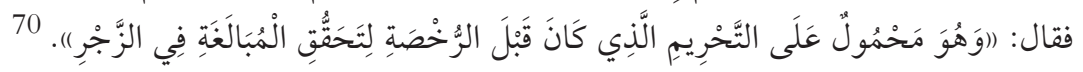

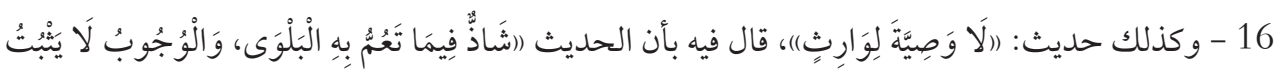

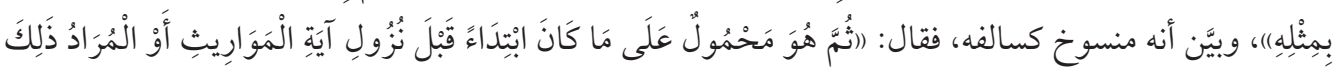

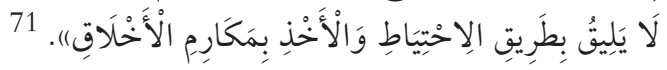

\section{رابعًا: من امتدادات المسألة في المذاهب الأخرى}

وكذلك فإن عددا من الفقهاء من المذاهب الأخرى قد قاموا بتخريج مسائل في مذهبهم على قاعدة عموم البلوى في الخبر الآحاد، أضرب على ذلك مثلى مثالين اثنين:

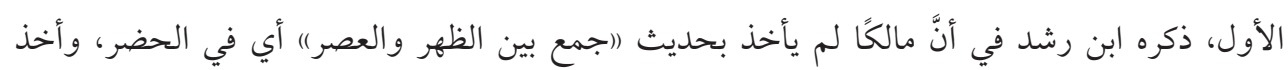

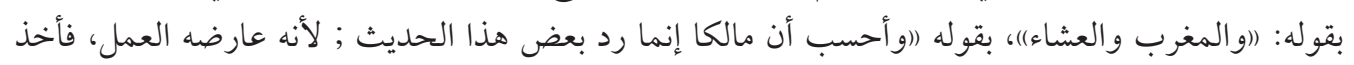

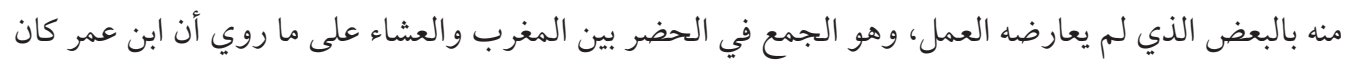

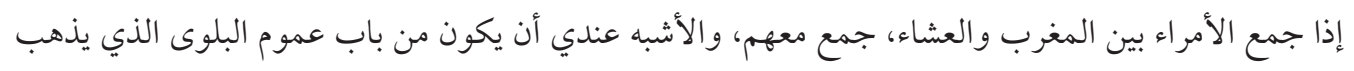

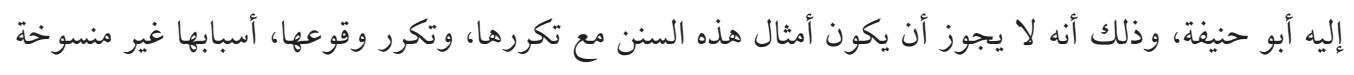

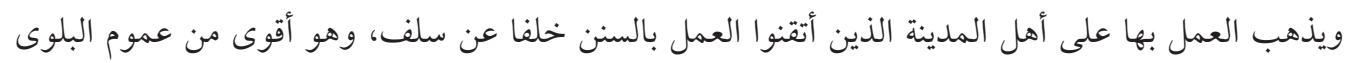

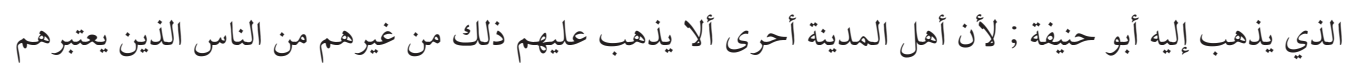
أبو حنيفة في طريق النقل).

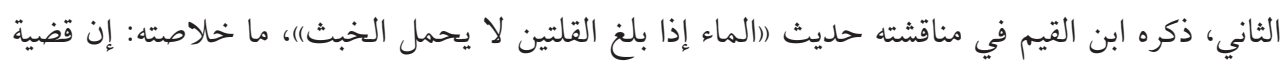

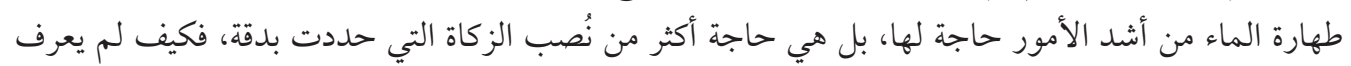

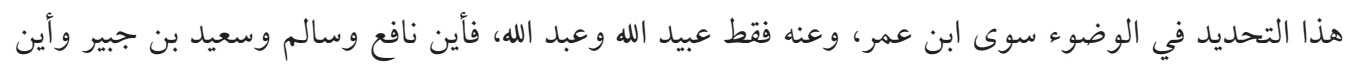

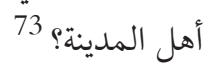

الثالث: كذا استدل بها في سياق رد حديث (إمامة علي" وغيره مما جرى فيه التوسع بمفهوم مسألة عموم

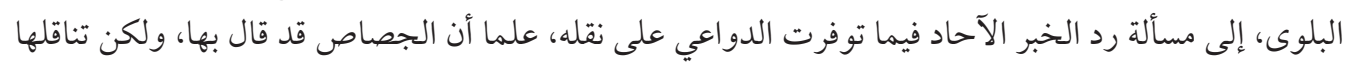

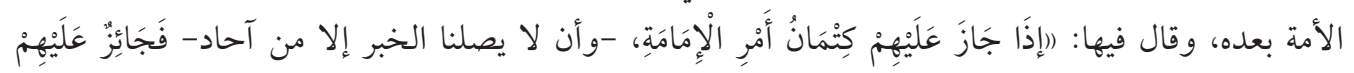

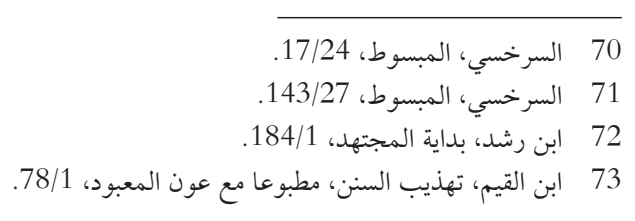




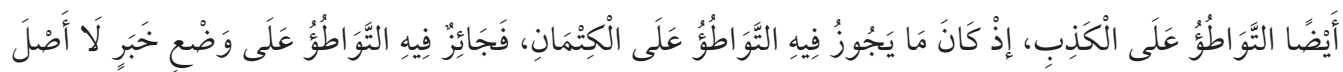

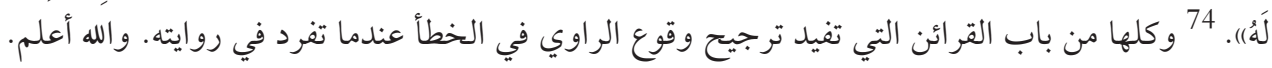

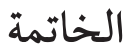

بعد هذه الجولة في كتب متقدمي الحنفية الأصول، يمكن لنا أن نجمل أهم الأفكار والنتائج بهذه النقاط الآتية:

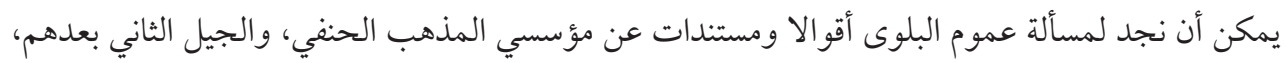

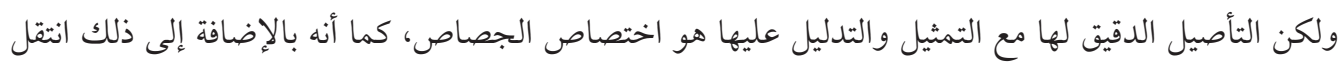

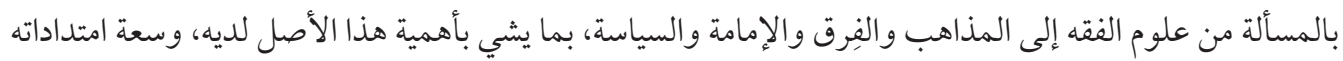

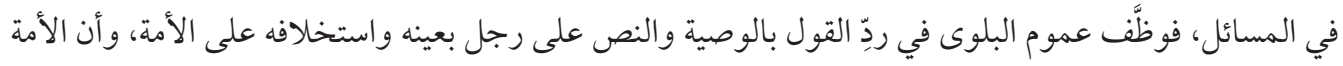

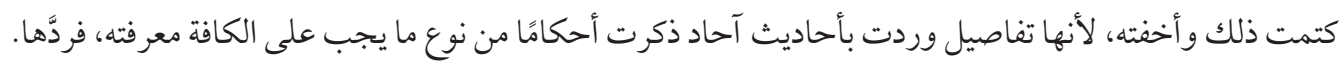

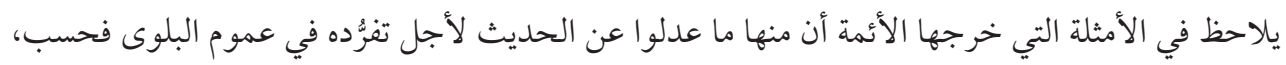

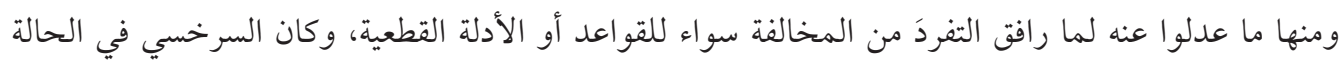

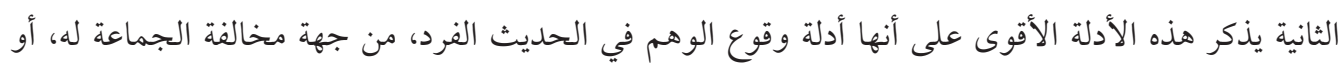

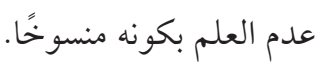
وبذلك العصر وأولئك الرجال يمكن أن يقال بأن نظرية عموم البلوى عند الحنفية قد اكتملت أركانها من

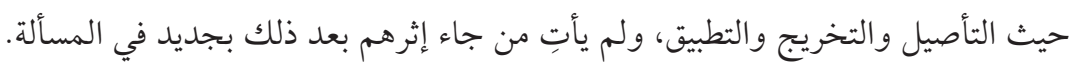

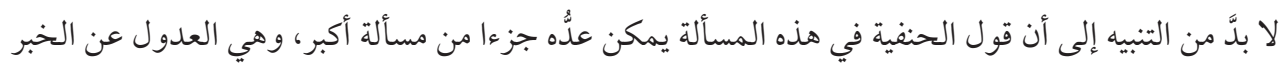

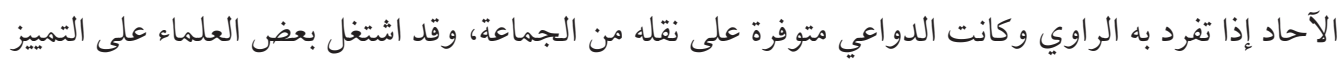

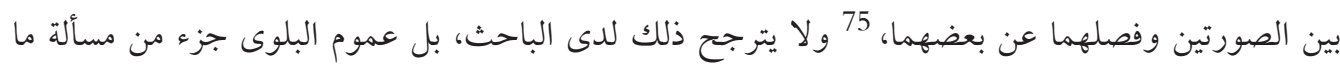

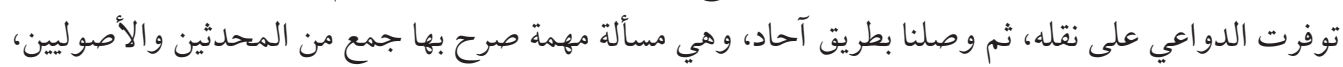
ولها تطبيقات دقيقة عندهم، أوصي بأن تُدرس وتؤصل بلد بدراسة مقار مقارنة بين المحدثين والحنفية. 76

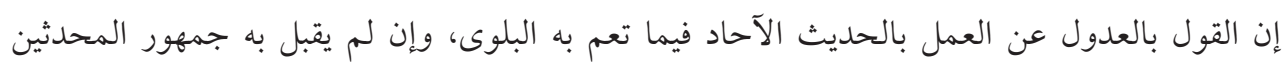

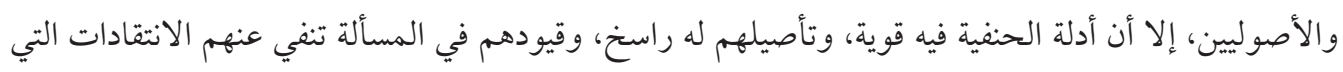

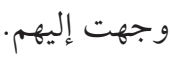

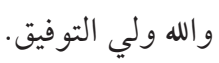

252/1 74

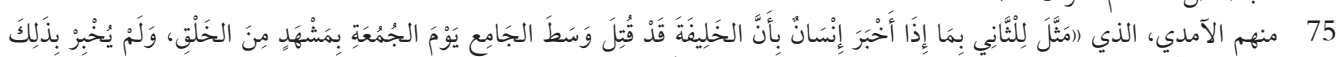

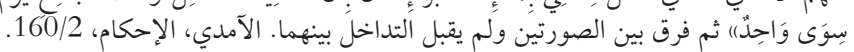
76 و وأسأل الله أن ييسر لنا فُ فرق ينمام هذه الدراسة. 


\section{المصادر}

ابن أمير الحاج، محمَّد بن محمَّد بن محمَّد، التقرير والتحبير، دار الكتب العلمية، (ب م)، ط2، 1403هـ- 1983م. ابن رشد، محمَّد بن أحمد، بداية المجتهد ونهاية المقتصد، مطبعة مصطفى البابي الحلبي وأولاده، مصر، الطبعة الرابعة،

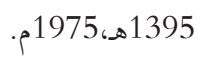

ابن عابدين، محمَّد أمين بن عمر، حاشية ابن عابدين، رد المختار على الدر المختار شرح تنوير الأبصار، دار الفكر للطباعة

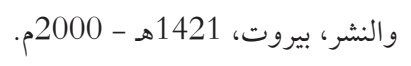

ابن فارس، أحمد بن فارس، معجم مقاييس اللغة، دار الفكر، (ب م)، (ب ط)، 1399هـ، 1979م.

ابن القيم، محمَّد بن أبي بكر، تهذيب السنن، مطبوعا مع عون المعبود شرح سنن أبي داود، دار الكتب العلمية، بيروت، ط2، 1415

ابن مازة، أبو المعالي برهان الدين محمود بن أحمد، المحيط البرهاني في الفقه النعماني، المحقق: عبد الكريم سامي الجندي،

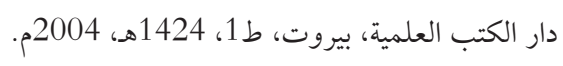

$$
\text { ابن منظور، محمَّد بن مكرم بن منظور المصري، لسان العرب، دار صادر، بيروت، ط1، (ب ت). }
$$

ابن نجيم، سراج الدين عمر بن إبراهيم، النهر الفائق، المحقق: أحمد عزو عناية، دار الكتب العلمية، (ب م)، ط1، 1422هـ -

$$
\text { ابن الهمام، كمال الدين محمَّد بن عبد الو احد السيواسي، شرح فتح القدير، دار الفكر، بيروت، (ب ط)، (ب ت). }
$$

أبو الحاج، صلاح، حكم حديث الآحاد فيما تعم به البلوى عند الحنفية وتطبيقاته في كتبهم، بحث منشور في مجلة المدونة

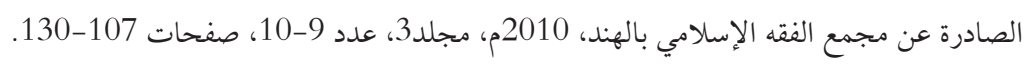

الآمدي، أبو الحسن علي بن أبي علي بن محمَّد، الإحكام في أصول الأحكام، تحقيق: سيد الجميلي، بيروت: دار الكتاب

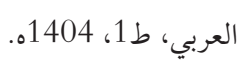

أمير بادشاه الحنفي، محمَّد أمين بن محمود البخاري، تيسير التحبير، مصطفى البابي الْحلَبي، مصر، (ب ط)، 1351هـ 1932م. الأنصاري اللكنوي، عبد العلي محمَّد، فواتح الرحموت بشرح مسلم الثبوت، تحقيق: عبد الله محمود محمَّد عمر، دار الكتب

$$
\text { العلمية، بيروت، (ب ط)، 1423ه، 2002م. }
$$

$$
\text { البخاري، عبد العزيز بن أحمد بن محمَّد، كشف الأسرار، دار الكتاب الإسلامي، (ب م)، (ب ط)، (ب ت). }
$$

البزدوي، علي بن محمَّد، كنز الوصول إلى معرفة الأصول، أو أصول البزدوي، مطبعة جاويد بريس، كراتشي، (ب ط)، (ب ت).

$$
\text { البصري، أبو الحسين، محمَّد بن علي الطيب، المعتمد، المحقق: خليل الميس، دار الكتب العلمية، بيروت، ط1، 1403ه. }
$$


الجصاص، أحمد بن علي أبو بكر الرازي، أحكام القرآن، تحقيق محمَّد الصادق قمحاوي، دار إحياء التراث العربي، بيروت،

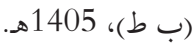

$$
\text { الفصول في الأصول، وزارة الأوقاف الكويتية، ط2، 1414هـ، 1994م. }
$$

شرح مختصر الطحاوي، تحقيق عصمت الله عنايت الله وآخرون، دار البشائر الإسلامية ودار السراج، بيروت، ط1،

الدوسري، مسلم، عموم البلوى دراسة نظرية تطبيقة، مكتبة الرشد، الرياض، ط1، 1420ه. السرخسي، محمَّد بن أحمد بن أبي سهل، أصول السرخسي، دار المعرفة، (ب م)، (ب ط)، (ب ت). شرح الكسب للشيباني، المحقق: سهيل زكار، الناشر: عبد الهادي حرصوني، دمشق، ط1، 1400ه. المبسوط، تحقيق: خليل محي الدين الميس، دار الفكر، بيروت، ط1، 1421هـ 2000م. الشاشي، نظام الدين أبو علي أحمد بن محمَّد، أصول الشاشي، دار الكتاب العربي، (ب م)، (ب ط)، (ب ت). الشيباني، محمَّد بن الحسن، الأصل، تحقيق الدكتور محمَّد بوينوكالن، دار ابن حزم، بيروت، ط1، 1433هـ- 2012م. الشيرازي، أبو اسحاق إبراهيم بن علي، اللمع في أصول الفقه، دار الكتب العلمية، بيروت، ط2، 2003م- 1424ه. العبادي، أحمد بن قاسم الشافعي، الآيات البينات على شرح جمع الجوامع للمحلي، تحقيق: زكريا عميرات، دار الكتب العلمية، بيروت، ط2، 2012م.

الغزالي، أبو حامد محمَّد بن محمَّد، المستصفى في علم الأصول، تحقيق: محمَّد عبد السلام عبد الشافي، دار الكتب العلمية، بيروت، 1413ه، طن 1413

القدوري، أحمد بن محمَّد، التجريد، تحقيق مركز الدراسات الفقهية والاقتصادية، القاهرة، دار السلام، ط2، 1427هـ - 2006م. القرني، عبد الرحمن، خبر الآحاد فيما تعم به البلوى، دراسة منشورة في موقع مسلم، الرابط: تاريخ الدخول: 2018/8/8م. http://almoslim.net/node/147129

كوارع، مصع(ب م)حمود، عموم البلوى وأثرها على خبر الواحد، رسالة ماجستير من كلية الشريعة والقانون في الجامعة

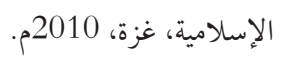

اللاحم، إبراهيم، تفرد الثقة بالحديث بين المتقدمين والمتأخرين، بحث منشور في مجلة الحكمة، السعودية، المجلد والعدد 24 محرم 1423ه

محمَّد بن عبد الكريم، خبر الواحد فيما تعم به البلوى وفيما يشترك في الإحساس به خلق كثير وتدعو الدواعي لنقله، رسالة

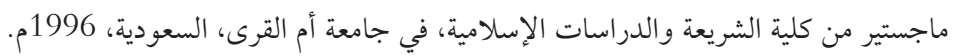

